Portland State University

PDXScholar

$1-1-2011$

\title{
Employee Age Differences in Formal Performance Feedback Reactions: Examining the Effects of Perceived Valence, Content, and Delivery
}

Gabriela Burlacu

Portland State University

Follow this and additional works at: https://pdxscholar.library.pdx.edu/open_access_etds Let us know how access to this document benefits you.

Recommended Citation

Burlacu, Gabriela, "Employee Age Differences in Formal Performance Feedback Reactions: Examining the Effects of Perceived Valence, Content, and Delivery" (2011). Dissertations and Theses. Paper 35.

https://doi.org/10.15760/etd.35

This Thesis is brought to you for free and open access. It has been accepted for inclusion in Dissertations and Theses by an authorized administrator of PDXScholar. Please contact us if we can make this document more accessible: pdxscholar@pdx.edu. 


\title{
Employee Age Differences in Formal Performance Feedback Reactions: Examining the Effects of Perceived Valence, Content, and Delivery
}

by

\author{
Gabriela Burlacu
}

A thesis submitted in partial fulfillment of the requirements for the degree of

\author{
Master of Science \\ in \\ Psychology
}

\author{
Thesis Committee: \\ Keith James, Chair \\ Donald Truxillo \\ Mo Wang
}

Portland State University
2011 


\begin{abstract}
As the nature of work is rapidly changing, organizations in developed nations all over the world are experiencing shifts in the age composition of their workforces. These changes, which include an aging workforce that is becoming increasingly agediverse, indicate that organizational researchers and practitioners need to be better aware of how age differences manifest themselves in the workplace and what implications this has for effective employee management. In the current study it is proposed that employees of different ages react differently to various elements of a formal performance feedback event. Specifically, Carstensen's developmental Socioemotional Selectivity Theory is used as a theoretical backing for explaining how and why employees of different ages perceive and react to performance feedback differently based on their perceptions of the valence, content quality, and delivery quality of the feedback. The results show evidence of age differences in feedback reactions, with younger adults being particularly concerned with information that will benefit them in the future and older adults being particularly concerned with information that conveys a positive relationship with one's supervisor. These findings have both conceptual and practical implications as we seek to build workplace aging theory and find ways to better manage and retain valuable employees of all ages in a changing world of work.
\end{abstract}


Age Differences and Feedback Reactions

Dedication

This thesis is dedicated to my grandparents, who have always given me the best reviews. 


\section{Acknowledgements}

I would like to acknowledge Dr. Keith James,

Dr. Mo Wang, and Dr. Donald Truxillo

for their endless help and guidance with this project. 
Age Differences and Feedback Reactions iv Table of Contents

Abstract

pg. i

Dedication

pg. ii

Acknowledgements

pg. iii

List of Tables

pg. vi

List of Figures

pg. vii

Introduction

pg. 1

Theoretical Background and Literature Review

pg. 5

Employee Feedback Reactions

pg. 5

Feedback and Justice

pg. 10

Age Differences in the Workplace

pg. 13

Socio-emotional Selectivity Theory

pg. 17

Cross-cultural Considerations

pg. 24

Hypotheses

pg. 29

Method

pg. 34

Participants and Procedure

pg. 34

Measures

pg. 35

Results

pg. 41

Descriptive Results

pg. 44

Model Summaries

pg. 46

Hypothesis 1 Results

pg. 48

Hypothesis 2 Results

pg. 48

Hypothesis 3 Results

pg. 49 
Hypothesis 4 Results

Hypothesis 5 Results

Hypothesis 6 Results

Exploratory Analyses

Analyses Run Without LMX

Discussion

Main Effects of Valence, Content, and Delivery

The Age by Valence Interaction

The Age by Valence by Delivery Interaction

Exploratory Analyses: Main Effects

Exploratory Analyses: Two-way Interactions

Exploratory Analyses: Three-way Interactions

Exploratory Analyses: Four-way Interaction

Limitations and Directions for Future Research

Theoretical Development

Conclusion

References pg. 50

pg. 52

pg. 53

pg. 57

pg. 71

pg. 74

pg. 75

pg. 77

pg. 78

pg. 82

pg. 85

pg. 89

pg. 93

pg. 96

pg. 106

pg. 113

pg. 117 


\section{List of Tables}

1. Pearson correlations among Affective, Cognitive, and Motivational Reaction Scales pg. 44

2. Hypothesis Support pg. 56 


\section{List of Figures}

1. Age by Valence Interaction: Satisfaction with Appraisal as outcome pg. 50

2. Age by Valence Interaction: Utility of Feedback as outcome pg. 51

3. Age by Valence Interaction: Motivational Reactions as outcome pg. 52

4. Age by Valence by Delivery Interaction: Satisfaction with Appraisal as outcome

5. Age by Valence by Delivery Interaction: Utility of Feedback as outcome

pg. 55

6. Age by Content Interaction: Utility of Feedback as outcome pg. 58

7. Age by Content Interaction: Motivational Reactions as outcome pg. 59

8. Age by Delivery Interaction: Utility of Feedback as outcome pg. 60

9. Age by Delivery Interaction: Motivational Reactions as outcome pg. 61

10. Valence by Delivery Interaction: Satisfaction with Appraisal as outcome

pg. 62

11. Valence by Delivery Interaction: Utility of Feedback as outcome pg. 63

12. Valence by Delivery Interaction: Motivational Reactions as outcome pg. 64

13. Age by Content by Delivery Interaction: Satisfaction with Appraisal as outcome

pg. 65

14. Age by Content by Delivery Interaction: Utility of Feedback as outcome 
Age Differences and Feedback Reactions viii

15. Age by Valence by Content by Delivery Interaction: Satisfaction with Appraisal as outcome pg. 68

16. Age by Valence by Content by Delivery Interaction: Utility of Feedback as outcome pg. 70

17. Age by Valence by Delivery Interaction: Satisfaction with Appraisal as outcome pg. 80

18. Age by Valence by Delivery Interaction: Utility of Feedback as outcome

pg. 81

19. Age by Content by Delivery Interaction: Satisfaction with Appraisal as outcome pg. 91

20. Age by Content by Delivery Interaction: Utility of Feedback as outcome pg. 92 
Age Differences and Feedback Reactions

Employee Age Differences in Formal Performance Feedback Reactions: Examining the Effects of Perceived Feedback Valence, Content, and Delivery

In a time of global organizational change involving increased virtualization and reduced face-to-fact contact in the workplace, one of the few social events that has remained constant over time is the delivery of formal employee performance feedback. Performance appraisals are widely used by supervisors in the hopes that their feedback will inspire subordinates to improve their weaknesses, build upon their strengths, and maximize their productivity and efficiency on the job. However, supervisors have likely noticed that their feedback does not always work as it is intended to; at times employees seem to ignore the feedback altogether. Worse still, it has been suggested that $40 \%$ of feedback events are actually associated with subsequent declines in performance rather than improvements (Kluger \& DeNisi, 1996).

Feedback researchers originally assumed that the laws of operant conditioning could be applied to the workplace. Specifically, it was assumed that positive feedback, working as a reward, would result in the increasing of desired employee behaviors, while negative feedback, acting as a punishment, would result in the cessation of undesired employee behaviors (Thorndike, 1927). This effect was once termed "one of the most accepted principles in psychology" (i.e., Pritchard, Jones, Roth, Stuebing, \& Ekeburg, 1988), but we now know that it doesn't always apply in the case of employee performance following a formal feedback event. 
Research attempts to better understand how feedback impacts subsequent employee performance have incorporated employee perceptions of the feedback. It has been suggested that the way employees feel or think about a feedback event will affect their behavior following the event, in addition to the more objective elements of the appraisal such as whether it was good or bad. For instance, several researchers have suggested that perceptions of feedback content, or how much relevant and useful information is presented along with the feedback, can impact how employees perform following feedback (Baron, 1993; Bianchi \& Ames, 2008; Ilgen, Fisher, \& Taylor, 1979). In addition, feedback delivery, or employee perceptions of how the feedbackgiver behaves and speaks to the employee while administering the feedback, has also been proposed to affect subsequent performance and behavior (Bianchi \& Ames, 2008). Research has consistently shown that objective and subjective feedback valence (i.e., impressions of whether the feedback is overall good or bad), content, and delivery all have an impact on employee perceptions of the feedback event and thus on their subsequent work behavior (Bianchi \& Ames, 2008; Brett \& Atwater, 2001; Pearce \& Porter, 1984; Pedler \& Boydell, 1980; Taylor, Fisher, \& Ilgen, 1984).

Although performance appraisal research has come a long way from the days of rewards and punishments, we still lack a concrete understanding of the link between feedback and subsequent employee performance. We need to build upon previous studies that have emphasized employee perceptions of feedback as an antecedent to post-feedback job performance, as psychological research has shown that perceptions 
and attitudes tend to lead to actions and behaviors (Ajzen \& Fishbein, 2000; Fazio, 1990; Prinz, 1997). Additionally, it is important for researchers to build upon studies that focus on the multiple components of feedback in order to gain a better understanding of how employee perceptions of valence, content, and delivery interact to form perceptions of the feedback event as a whole. While feedback studies have been historically focused on valence as a predetermining factor of employee behavior, much can be gained from examining the effects of other facets of the feedback event as well. Finally, further research needs to be conducted in areas of feedback perceptions and reactions that have not been previously examined. For instance, very little research has addressed the question of whether there are individual differences that may impact how employees perceive the different elements of a feedback event. Such relationships should be better understood if we are to fully comprehend how we can use feedback literature to assist supervisors and other organizational entities in delivering better and more effective performance appraisals.

Along these lines, one significant social issue that has resulted from the changing nature of the workforce is the prevalence of employees of different ages working together within the same organization. Organizations worldwide are facing an aging workforce that is becoming progressively more age-diverse (Liebold \& Voelpel, 2006). Although research has indicated that age differences do exist in the workplace, from differences in motivation (Kanfer \& Ackerman, 2004) to competition (Wong, Gardiner, Lang, \& Coulon, 2008) to job satisfaction (Barnes-Farrell \& Matthews, 
2007; Smola \& Sutton, 2002), virtually no studies have been conducted on age differences in employee feedback reactions. If such differences are found, this will not only impact the way human resources research is conducted, but the way organizational practice is conducted as well. Aside from contributing to the existing literature, if an examination of this important individual difference reveals variations in how employees of different ages perceive performance feedback, this will affect the way feedback is delivered and administered in organizations. For this reason it is both conceptually and practically important to understand the mechanisms underlying performance feedback reactions and employee age differences.

The current study focuses on these differences as a function of the different elements of a feedback event. In this study, I examine employee perceptions of the valence, content, and delivery of a formal appraisal event and how these perceptions vary according to employee age. The results will add to both the feedback reactions literature and the aging literature by tying these important and prevalent workplace issues together. First, to my knowledge, this study is the first of its kind to connect an important human resources function (the provision of performance feedback) to workplace age differences. Second, this study builds upon previous feedback literature by adding a time-lagged component. While many researchers have assessed employee attitudes immediately following a feedback event, few have undertaken the task of examining how these attitudes and perceptions reveal themselves over time. I propose that performance feedback is administered with the goal of affecting 
performance and behavior over a longer time span. Thus, using a time-lagged design we can better determine the temporal sequence of employee feedback perceptions and how they manifest themselves through employees' reactions over time.

\section{Theoretical Background and Literature Review}

\section{Employee Feedback Reactions}

As the feedback literature has evolved, it has become widely recognized that feedback receivers' attitudes, emotions, and biases need to be considered in order to gain a full understanding of why and when performance appraisals are effective at improving performance. Studies along these lines have examined feedback reactions as a pivotal variable in understanding subsequent behavior change (Bianchi \& Ames, 2008; Brett \& Atwater, 2001; Pearce \& Porter, 1984). One potential influence on employee feedback reactions that has received attention in the literature is the source of the feedback. Certainly research suggests that the source of the feedback is likely to affect the validity of the performance appraisal: self and peer ratings are often fraught with distortion and bias (Cascio \& Aguinis, 2005; Holzbach, 1978; Scullen, Mount, \& Goff, 2000). Organizational scholars have consistently cited supervisor ratings to be the most valid (Bianchi \& Ames, 2008; Borman, 1987; Hobson \& Gibson, 1983; Scullen et al., 2000), and considerably more favored by employees in terms of specificity and credibility (Albright \& Levy, 1995; Ilgen et al., 1979). Supervisor ratings also tend to be the most common (Erdogan, 2002), and thus the current study is focused on employee reactions to supervisor-administered appraisals. 
Feedback reactions research has focused generally on three types of reactions: affective, cognitive, and motivational. Affective reactions, not surprisingly, refer to how the feedback makes an employee feel. Anyone who has ever received a formal performance appraisal can understand how perceptions of the valence of the feedback, or whether it is generally good or bad, can garner an emotional response. Positive feedback has been associated in the literature with pleasantness, satisfaction with the appraisal and the appraisal process, and pride (Brett \& Atwater, 2001; Kluger \& DeNisi, 1996; Mabe \& West, 1982; Shrauger, 1975). Negative feedback, by contrast, has been associated with negative arousal, cognitive dissonance, and mistrust (Brett \& Atwater, 2001; Festinger, 1954; Kluger \& DeNisi, 1996; Taylor et al., 1984).

Considerably less research has been focused on other elements of the feedback event and how these might yield affective reactions for employees. Perceptions of feedback content, for instance, refer to employee impressions of the information provided along with the feedback itself. Researchers have found that when feedback is perceived as being timely, specific, and credible, employees report higher satisfaction with the feedback (Baron, 1993; Ilgen et al., 1979). Bianchi and Ames (2008) found that perceptions of high-quality feedback content predicted positive affective judgments and satisfaction with the feedback. Similarly, Brett and Atwater (2001) found that feedback that was perceived as being credible yielded more positive affective reactions. 
Perceptions of feedback delivery refer to employee impressions of the feedback giver's demeanor when delivering the feedback (for instance, impressions of the degree to which the feedback giver is open, honest, encouraging, and prepared). Bianchi and Ames (2008) found that impressions of high-quality delivery also predicted positive affective judgments and satisfaction with the feedback. Although few studies have examined this link, research regarding supervisor treatment of employees in the workplace reveals an affective connection as well. Employee perceptions of being treated poorly at work have been linked to negative affect (Brett \& Atwater, 2001; Masterson, Lewis, Goldman, \& Taylor, 2000), while perceptions of being treated well at work have been linked to job satisfaction and organizational commitment (Folger \& Cropanzano, 1998; Greenberg, 1990).

Cognitive reactions refer broadly to what an employee thinks about a feedback event. Specifically, cognitive reactions are measured by assessing the degree to which workers view the feedback as being useful to their development as employees. Certainly research has shown that feedback valence can impact these perceptions. Feedback that is perceived as being positive is generally also perceived as being more useful (Baron, 1993; Podsakoff \& Farh, 1989) and credible (Brett \& Atwater, 2001). Conversely, feedback that is perceived as being more negative than expected is viewed as less credible and less useful (Brett \& Atwater, 2001). Very little research has examined cognitive reactions to perceptions of feedback content and delivery, but there is some evidence to suggest that these elements of feedback yield these types of 
reactions as well. Bianchi and Ames (2008), for instance, found that employee ratings of both content and delivery predicted ratings of how useful the feedback was.

Finally, motivational reactions to a feedback event refer to how motivated employees feel in their jobs specifically following the feedback. This relates to research and theory regarding work motivation in general. Theoretically, work motivation is derived in part from employees' expectancies that their performance will lead to a desired outcome (Arnold, 1981), as well as from attributes of the employees themselves (Lee, Sheldon, \& Turban, 2003) and from elements of the environment and entities within that environment (Steers, Porter, \& Bigley, 1996). Research has shown the effects of employee achievement striving and status striving on motivation and performance (Barrick, Stewart, \& Pitrowski, 2002; Wiggins \& Trapnell, 1996) and that goal-setting plays a key role in motivation in that goals give employees something to work toward (Locke \& Latham, 2002; Locke \& Latham, 2006). Motivational reactions to performance feedback operate somewhat similarly. Formal performance feedback may convey supervisor support for development, or it may invite employees to set goals for their own improvement. Regardless of the mechanisms, there are elements within these appraisal events that do (or do not) evoke a motivational response within the recipients. Research has shown that both positive and negative feedback can be motivating. For instance, negative feedback has been shown to result in employees setting higher goals and performing better on the job, but only when the feedback is perceived as being credible (Podsakoff \& Farh, 
1989). Perceptions of feedback content have also been shown to impact motivation following the feedback. Brett and Atwater (2001) found that when employees perceived feedback as being credible and useful, a blind facilitator was more likely to label them as being "development-focused" in an hour-long discussion that took place two to four weeks after the written feedback was collected. Very little research has examined the motivational impact of perceptions of feedback delivery, but Bianchi and Ames (2008) did find significant positive relationships between post-feedback work motivation and perceptions of valence, content, and delivery.

There are aspects of a feedback event besides perceptions of valence, content, and delivery that may impact the affective, cognitive, and motivational reactions employees have to the feedback. Along these lines, researchers have examined the social dynamics between supervisors and their subordinates and how these manifest themselves in a performance appraisal setting (Cascio \& Aguinis, 2005; Lefkowitz, 2000; Schraeder \& Simpson, 2006; Strauss, Barrick, \& Connerley, 2001).

Characteristics of the feedback giver, for instance, or the relationship between the feedback giver and the employee may cause different employees to perceive the same feedback differently. Rater similarity and rater familiarity in particular have been shown to influence the degree to which an employee likes a supervisor and thus could impact how he or she views the feedback that supervisor is administering. An employee that has worked with a supervisor for a long period of time may have more positive reactions to that supervisor's evaluations (Cascio \& Aguinis, 2005). 
Likewise, a supervisor that is similar to an employee in gender or age may also yield higher employee reactions of that supervisor's appraisal (Avery, McKay, \& Wilson, 2007). The supervisor-employee relationship can have a strong impact on employee perceptions of performance appraisal, beyond elements of the appraisal itself (Graen \& Uhl-Bien, 1995); the better the employee perceives the relationship between himself and his supervisor to be, the greater the chance that the employee will perceive the feedback coming from that supervisor as being satisfying, useful, and motivating (Levy \& Williams, 2004).

Feedback and Justice

Research examining organizational justice in the context of performance appraisal has spanned several decades. Certainly fairness is a staple of an effective performance appraisal system in any organization (Jacobs, Kafry, \& Zedeck, 1980). But the literature also suggests that employee perceptions of the justice regarding their performance appraisals impact their reactions to that appraisal, and presumably their subsequent work behavior and performance. Justice perceptions in general are associated with attitudes such as trust in management and organizational commitment (Konovsky \& Cropanzano, 1991). Justice perceptions regarding feedback are associated with more favorable attributions of the rater, more favorable reactions toward the feedback, and more favorable reactions toward the job and organization, in general, even when feedback is negative (Leung, Su, \& Morris, 2001). 
Age Differences and Feedback Reactions

Initially researchers focused on the distributive and procedural justice of feedback events. Distributive justice refers to the arrival at an outcome that is fair, while procedural justice refers more to the fairness of the process itself (Colquitt, 2001). Greenberg (1986) sampled middle managers from three organizations and found that the determinants of justice regarding performance appraisal that they deemed important could be placed into two categories: distributive (i.e., the degree to which the final rating based on performance was fair) and procedural (i.e., consistent application of standards). Research on distributive and procedural justice perceptions has shown that employee perceptions of the degree to which these justice elements are present in a feedback event will impact their impressions of the event and their behavior thereafter (Erdogan, 2002).

More recently, the construct of procedural justice has been separated into two distinct categories: procedural justice, per se, and interactional justice, which refers broadly to "the quality of interpersonal treatment received during the enactment of organizational procedures" (Masterson, Byrne, \& Mao, 2005). Interactional justice has been further divided into two categories: informational justice, which refers to the degree to which relevant information regarding an organizational procedure or outcome is distributed to an employee, and interpersonal justice, which refers to how organizational entities (for instance, supervisors), treat an employee (Colquitt, Conlon, Wesson, Porter, \& Ng, 2001; Masterson et al., 2005). 
The latter two dimensions of organizational justice can be directly applied to the elements of a feedback event. Informational justice behaviors, according to Masterson et al. (2005), include providing reasonable explanations for decisions and being candid in communications with an employee. Thus, if an employee perceives that a supervisor provides him or her with relevant, credible information during a feedback event, then he or she perceives high informational justice. This construct is strikingly similar to the idea of perceptions of feedback content: as with informational justice, feedback content perceptions consist of impressions of the quality and quantity of the information presented during a feedback event.

One widely-used measure of informational justice can be found in Colquitt's Organizational Justice Scale (2001). As an example, one item within this subscale requires respondents to indicate the degree to which an entity within his or her organization (for instance, the supervisor) provides reasonable explanations regarding an outcome. Another item requires respondents to indicate whether or not the same organizational entity has explained an outcome thoroughly. These are all elements that should be present within a performance appraisal event if the content of the feedback that occurs during that event is high in quality. Thus, it can be said that perceptions of feedback content are in fact perceptions of feedback-specific informational justice.

Likewise, interpersonal justice behaviors include treating others with respect and dignity and considering others' viewpoints (Masterson et al., 2005). These behaviors 
are similar to those that employees perceive as being high-quality feedback delivery; a supervisor who is perceived to be open, encouraging, kind, and respectful is one who delivers feedback well. For instance, Colquitt's interpersonal justice subscale (2001) contains items that require respondents to indicate the degree to which an organizational entity (again, possibly the supervisor) treats them with respect and refrains from making improper or irrelevant remarks. These are elements that one would expect to be present in a performance feedback event in which the quality of the delivery given by the supervisor is good. Thus, it can also be said that perceptions of feedback delivery are, in fact, perceptions of interpersonal justice regarding the feedback event. Perceptions of informational and interpersonal justice regarding a feedback event are likely to impact employee reactions and subsequent behaviors by affecting their affective, cognitive, and motivational impressions of the feedback. Age Differences in the Workplace

As was previously mentioned, organizations worldwide are experiencing shifts in their working populations, resulting in aging workforces that are simultaneously becoming exceptionally age-diverse (Liebold \& Voelpel, 2006; Walker, 2005). These trends indicate that researchers and practitioners need to be aware of the needs and capabilities of employees of all ages as they attempt to find ways to successfully manage this new workforce.

Developmental researchers have long tracked the variable of age and how it manifests itself in terms of individuals' goals, emotions, and behaviors. Certainly 
there is no disagreement that people experience changes in these aspects with age, but there is some disagreement as to the mechanisms involved and how prevalent and salient these changes are in a specialized context such as the workplace. Research has shown that age differences in work attitudes and values do exist in the workplace (Kanfer \& Ackerman, 2004; Karp, Fuller, \& Sirias, 2001; Smola \& Sutton, 2002). However, few organizational researchers have applied general developmental theories and frameworks to the study of age differences in the workplace. This application can be useful as we attempt to understand the dynamics of age and workplace thoughts, emotions, attitudes, and behaviors in a changing workforce.

Developmental theorists differ in their views of aging in that some advocate theories that have a very optimistic view of aging, while some advocate theories that focus on the detriments and losses associated with age. One such theory, Disengagement Theory, suggests that as individuals age their relationships with other members and entities of society are severed or altered in quality, such that older adults are "disengaging" from society. This theory has received empirical support: research has shown that as people age their social circles decrease in number and they experience greater distance from society (Larson, Zuzanek, \& Mannell, 1985; McAuley, Blissmer, Marquez, Jerome, Kramer, \& Katula, 2000). Certainly this disengagement and distancing could have implications for the performance of aging adults in the workplace, as we might expect that older adults will be more likely to withdraw and engage in counter-work behaviors as a result of their disengaging. 
However, research has shown that this is not necessarily the case (Avolio, Waldman, \& McDaniel, 1990; Ng \& Feldman, 2008; Warr, 1994).

As an alternative, some theorists suggest that the process of aging is associated with continuity and not with disengagement. Continuity Theory states that as adults age, they strive to continue along in the same behaviors, activities, personalities, and relationships. By maintaining these aspects of their lives, aging adults maintain a connection with their past experiences (Atchley, 1989). Indeed, there is some empirical evidence that suggests this effect: research has shown that many older adults are able to maintain intelligence (Gold, Andres, Etezadi, Arbuckle, Schwartzman, \& Chaikelson, 1995), continuity in personality traits (Capsi, Roberts, \& Shiner, 2005; Field \& Millsap, 1991), and continuity in close relationships (Field, 1999; House, Lantz, \& Herd, 2005). Researchers have additionally found that older adults tend to maintain social participation following widowhood (Utz, Carr, Nesse, \& Wortman, 2002) and tend to show continuity in religious activity participation over the lifespan (Levin \& Chatters, 1998). One qualitative study revealed that older adults essentially perceive themselves as the same person throughout the lifespan, and there is significant stability in how they view specific characteristics about themselves (Troll \& Skaff, 1997). Again, this theory has important implications for the workplace: older adults should be more concerned with maintaining good work relationships and continuity of job performance. Aging researchers have found that this is often the case; older employees tend to display more safety behaviors, fewer 
withdrawal behaviors, and continue behaviors that maintain productivity and efficiency (Ng \& Feldman, 2008).

The more optimistic Continuity Theory has received much attention in the literature, and has spawned other more specific aging theories that can also be considered in the context of the workplace. For instance, researchers have suggested that many of the different continuity-focused attitudes and behaviors we see with age are actually a result of the reorganization of goals that comes with age. One such theory, the Selection, Optimization, and Compensation (SOC) theory, suggests that development across the lifespan entails processes that maximize gains and minimize losses (Baltes \& Baltes, 1990; Freund \& Baltes, 2000). Researchers in this camp have suggested that younger adults, who are typically on a trajectory of growth or gains in resources, tend to engage in proportionally more processes and activities geared toward optimization or gains, while older adults, who are typically faced with more losses, tend to engage in more processes and activities geared toward preservation and counteracting losses (compensation). In one such study, older and younger adults were asked to engage in a sensori-motor task involving two conditions: one in which the optimization of skills was emphasized, and one in which compensation for poor performance was emphasized. As predicted, younger adults were significantly more likely to be more persistent in the condition that emphasized optimization of skills, while older adults were significantly more persistent in the condition in which compensation for prior performance was emphasized (Freund, 2006). Ebner, Freund, 
and Baltes (2005) found that younger adults tend to rate their personal goals as having a stronger focus on growth and optimization, while older adults tend to report personal goals that have a greater focus on maintenance and prevention of loss. In addition, Ogilvie, Rose, and Heppen (2001) found that blind external raters were more likely to rate older adults' personal goals as being compensation-focused, showing the validity of this theory across measurement and sample methods.

The tenets of SOC theory have implications for contexts such as the workplace (Freund, 2006). We might expect that younger adults, having goals that are centered around growth, will be more interested in career advancement and be more oriented toward learning and acquiring knowledge. Older adults, by contrast, are likely to display tendencies that are consistent with the conclusions of continuity theories of aging: they should be less concerned with promotional opportunities and training and more concerned with maintaining the relationships and positions they currently hold. This theory can be a very helpful beginning toward understanding the behaviors and goals of adults of all ages in the workplace, but does little to explain the many cognitive, affective, and attitudinal variables that may impact employee feedback perceptions.

Socio-emotional Selectivity Theory

One socio-developmental theory that has been understudied in the context of the workplace is Carstensen's Socio-emotional Selectivity Theory (SST; Carstensen, 1991). A key tenet of SST is that a basic awareness of passage through different life 
stages is ubiquitous in all cultures and people, and that this awareness will have implications for people's emotions, cognitions, and motivations (Carstensen, 1991; Carstensen, Isaacowitz, \& Charles, 1999). SST also posits that individuals are typically agentic in that they set goals and behave in ways that are likely to help them achieve those goals (Carstensen et al, 1999). Put together, these two principles indicate that where one is in his or her "life time" (i.e., whether one is relatively young or relatively old) strongly shapes the types of goals an individual will pursue. Specifically, the theory posits that younger individuals are closer to the beginning of their life cycles, and thus view "time" as time since birth. Thus, their goals will be future-oriented: they will aim toward knowledge acquisition, career planning, and the development of new social relationships that will pay off in the future (Carstensen, 1991). Older individuals, by contrast, view "time" as time left in life. Thus, they will have more present-oriented goals: they aim toward regulating their emotions to be positive, pursue emotionally gratifying relationships with others, and engage in activities that will benefit them relatively immediately (Carstensen, 1991). Overall, according to Carstensen's theory (1991; 1992), older adults focus more on socioemotional outcomes, while younger adults are more driven by skill, knowledge, novelty, and opportunity development, and thus are more information-oriented. The theory is supported by a number of empirical studies. Carstensen and TurkCharles (1994), for instance, administered a memory test to participants of all ages and found that the proportion of emotional material that was recalled significantly 
increased for each successive age group. Similarly, Hashtroudi, Johnson, and Chrosniak (1990) conducted a study in which older and younger participants were asked to read passages about everyday situations and later recall the content. Older adults recalled significantly more feelings and evaluative statements than their younger counterparts. After conducting a similar study, Turk-Charles, Mather, and Carstensen (2003) suggested that older adults' memory patterns resembled those of younger adults who were asked specifically to attend to emotional information, leading them to conclude that older adults spontaneously attend to emotional material. Taken together, these studies indicate that older adults are indeed more emotionally focused.

Empirical studies have revealed support for the social aspect of SST as well. Older adults do generally report both having smaller social circles and being more satisfied with those social networks (Carstensen \& Mikels, 2005). Younger adults, by contrast, tend to have larger social circles comprised of people with whom they feel less emotionally attached (Carstensen, 1992; Carstensen \& Mikels, 2005), and tend to have a greater desire for learning, acquiring information, and obtaining new social connections (Carstensen, 1991; 1992). In a study that required participants to describe their social relationships and classify them as being close relationships, problematic relationships, or ambivalent relationships (possessing qualities of both closeness and problematic relationships), it was found that older adults were more likely to classify their familial and social ties as being close, while younger adults were more likely to 
classify these relationships as being ambivalent and were also more likely than older adults to describe acquaintances in this exercise (Fingerman, Hay, \& Birditt, 2004). Thus, the researchers concluded that this was a possible reflection of the tenets of SST: older adults placed greater emphasis on their closer social relationships and regarded these relationships more positively than did younger adults.

No specific measure of SST currently exists, but its measurement in the literature has been conducted based on its underlying constructs. One important tenet of SST, for instance, is that older adults tend to be more present-oriented while younger adults tend to be more future-oriented (Carstensen, 1991). Thus, the Future Time Perspective (FTP) scale was developed to assess individuals' conceptualization of time. Indeed, researchers conducting a validity study of the FTP scale found support for the tenets of SST: viewing time as more limited was highly correlated with age, and also highly correlated with emotional regulation. Conversely, viewing time as being more open-ended was strongly correlated with age in a negative direction, and this was also strongly correlated (in a positive direction) with the prioritization of instrumental or knowledge-related goals (Lang \& Carstensen, 2002).

Another important tenet of SST is the idea that older adults will have fewer social relationships than younger adults, but that these relationships will be more emotionally satisfying and gratifying. Indeed, this has been demonstrated in the research: measures such as the Social Convoy Measure (Kahn \& Antonucci, 1980), which requires respondents to list close relationships and acquaintanceships, have 
revealed the decreasing numbers of older adults' core social circles (Fung, Carstsensen, \& Lang, 2001). Additionally, research has also shown with a number of happiness and satisfaction measures the concurrent increase in satisfaction with social circles that older adults experience (Carstensen, 1992; Fung et al., 2001).

Qualitative vignettes have been utilized to determine older adults' attention to emotionally-charged material (Carstensen \& Turk-Charles, 1994), as well as to study the effect of socio-emotional preferences independently of age. For instance, Fung, Carstensen, and Lutz (1999) conducted a study requiring participants to read vignettes that described time constraints such as the moving away of the participant. In this condition, the effect of age on social preferences disappeared: younger adults were just as likely as older adults to desire social contact with close partners.

While considerably less research has examined SST in the workplace, several studies suggest that age-related goals do manifest themselves in an occupational setting. For instance, research has suggested that older adults are less open to new experiences, less active in pursuing new social relationships, and less careerdevelopment oriented, while younger adults tend to have a "learning orientation" and thus use challenges as learning and development opportunities (Kanfer \& Ackerman, 2004). In addition, research has shown that younger employees are typically more competitive rather than cooperative (Wong et al., 2008), and older adults typically display more affective commitment to their organization while younger employees tend to place more importance on "employability" and opportunity for advancement 
Age Differences and Feedback Reactions

(Barnes-Farrell \& Matthews, 2007; D’Amato \& Herzfeldt, 2008). While researchers have established that employees of different ages do differ in terms of their workplace attitudes, goals, and values, virtually no research has examined these age differences in regard to important human resources functions such as formal performance appraisals. In light of the wide-scale changing age composition of the workforce, the current research seeks to examine age differences in this context.

SST can be directly applied to employee reactions to feedback. Researchers have linked feedback valence to employee emotions in the feedback reactions literature (Kluger \& DeNisi, 1996). Research has consistently shown that positive feedback is associated with satisfaction with the appraisal and the appraisal process (Brett \& Atwater, 2001; Dobbins, Cardy, \& Platz-Vieno, 1990; Inderrieden, Keaveny, \& Allen, 1998; Landy \& Farr, 1980). In addition, negative feedback is associated with negative affective reactions on the part of the employee (Russell, 1980), and negative feedback may actually be perceived as threatening (Taylor et al., 1984). These effects have not, however, been examined for whether they apply equally to both younger and older workers. Given that SST suggests that older adults are more emotionallyfocused, older adults should have more extreme reactions to positive and negative valence than younger adults.

Likewise, feedback literature has linked feedback content with employee perceptions that the feedback is constructive and development-focused. Research has shown that when feedback is perceived as credible, negative feedback leads people to 
set higher goals and perform better in the workplace (Podsakoff \& Farh, 1989). In addition, it has been suggested that, whether the feedback event is positive or negative, feedback content affects employee reactions such that a higher quality of content presented in the feedback event is associated with perceptions of feedback usefulness, motivation, and development intentions (Bianchi \& Ames, 2008). Again, however, these effects have not been tested for whether they are moderated by employee age. SST suggests that younger adults, whose goals are centered on future development and career advancement, will be more affected by feedback content than will older adults.

Lastly, SST can be clearly linked to employee reactions to feedback delivery. The manner in which one is treated by a supervisor or an organization relates directly to research on interpersonal justice, which suggests that when employees are treated better, they will generally be more satisfied in the workplace (Erdogan, 2002; Folger \& Cropanzano, 1998; Greenburg, 1993; Konovksy \& Cropanzano, 1991). Being treated with disrespect, however, can be a highly emotional event as well (Brett \& Atwater, 2001), in that employees generally have very negative affective reactions to poor or unjust interpersonal treatment at work. Thus, because employees exhibit emotional reactions to the way they are treated by their supervisors and the organization (Masterson et al., 2000), older adults should be more affected by the quality of delivery in a feedback event than younger adults. Additionally, SST posits that older adults are seeking more gratifying social relationships than are younger 
adults (Carstensen, 1992). Thus, it is expected that older adults will be more strongly affected by delivery, as good delivery indicates the presence of a positive relationship with their supervisor while poor delivery indicates its absence.

\section{Cross-Cultural Considerations}

It is possible that older adults, who in many ways are "pushed out" by society in the United States as they age (Utz et al., 2002) may display behaviors and attitudes that are consistent with compensation and emotional and social regulation because they simply do not exist in an environment that allows them to pursue goals of growth or learning. Additionally, it is possible that the growth and learning orientations that researchers have observed in younger adults are a product of the fast-paced current business model that dominates organizational activity in the United States (Liepold \& Voelpel, 2006). Thus, cultural and contextual differences need to be taken into consideration when studying these phenomena in different nations for whom age and work may have different meanings.

One such nation, China, is experiencing an aging of the workforce similar to that which is occurring in the United States (Liepold \& Voelpel, 2006). However, these two nations are very dissimilar in terms of how they view aging individuals, in their stages and histories of economic development, and in how they conduct business (Hofstede, 1980). One means of comparing the two nations is through the lens of Hofstede's culture dimensions (Hofstede \& Bond, 1984). Through this framework we 
can assess their differences along several different cultural-value dimensions that may affect age differences in the workplace.

First, Hofstede's examinations of China and the United States have revealed that the two nations differ greatly on power distance. China, being a nation that is high on the power distance dimension, is likely to host organizations that are very structured in terms of their hierarchies and leadership. Less powerful members of institutions and organizations are more likely to accept this power distance in China, whereas in the United States, this power distance is generally much smaller and decreasing (House, Hanges, Javidan, Dorfman, \& Gupta, 2004). The two nations also differ in terms of their views of human nature and citizens' obligations toward one another. China has a very collectivistic worldview in which its citizens are expected to engage in behaviors and activities that help the population as a whole. The United States, by contrast, adopts a very individualistic worldview in which people are expected mostly to take care of themselves. Although research has found that American's institutional (organizational) collectivistic values are relatively high, their collectivistic practices remain significantly below other nations and below global averages (Gelfand, Bwahuk, Nishii, \& Bechtold, 2004). A more recent dimension on which countries can differ is that of long term versus short term time orientation. A nation with a long term orientation, such as China, is one that has great respect for past traditions, although economic and political changes have occurred relatively recently in China that may be altering time-orientation there ( $\mathrm{Li}$, Tsui, \& Weldon, 2000). People in the 
United States, however, do not adopt a long-term worldview (Hofstede suggests that this is because the United States is too young to have had any long-term traditional commitments), and thus U.S. organizations and their members seem more oriented toward short-term goals and benefits. Indeed a recent study of the practices and values of 62 nations found that Americans are more likely to be future-oriented and short term-focused, while the Chinese reported higher collectivism values and practices within institutions and in general, but low levels of values and practices regarding future orientation (House et al., 2004).

All of these differences can impact the way organizations are formed and work is conducted in each nation. These differences (particularly power distance differences and differences along the collectivistic/individualistic axis) can impact the way job performance is measured and appraised. They can especially impact employee perceptions of and reactions to performance feedback, as Chinese employees may feel that they do not have the right to appraise their supervisors' evaluations negatively. For these reasons, cross-cultural considerations need to be taken into account when conducting organizational research abroad, and issues of confidentiality and informed consent are particularly important.

While there is the possibility of cultural and other cross-national differences in developmental individual differences in organizations, the case can also be made for expecting the same effects of age on performance appraisal perceptions regardless of nation or culture. Many developmental theories (SST included) are argued to apply 
liberally to all human beings, and do not specify to any one cultural or national context. SST posits that all humans should adopt a more present-focused or futurefocused orientation depending on their age; all older adults should be more emotionally-focused and seeking of gratifying social relationships, while all younger adults should be more information-focused and driven toward learning, opportunity, and change. Indeed, empirical evidence has shown that the effects of SST have been replicated among other cultures: one study found that among Taiwanese and mainland Chinese residents, older adults were more likely than younger adults to prefer the company of familiar social partners who were likely to provide emotionally close social interactions (Fung, Lai, \& Ng, 2001). Mainland Chinese, who typically have a shorter life expectancy than Taiwanese as a group, were even more likely to exhibit this preference than Taiwanese participants. Similarly, Fung et al. (1999) conducted a study in which citizens of both the United States and Hong Kong reliably showed expected age differences in social preferences. Fung et al. (2001) conducted a study in which they assessed the social preferences of European Americans and African Americans (two populations with very different social structures). Again, they found that the age-related tenets of SST held up across ethnic groups.

Overall, SST suggests that across cultural contexts we should be able to see an affect of age such that older adults in all nations are similar in terms of their goals and socio-emotional preferences, but are different on those things in important ways from younger adults. In this study I aim not only to tie employee feedback reactions and 
workplace age differences together in a novel way, but also to assess whether the tenets of SST can explain effects of age on performance appraisal reactions in China, which would support a universal developmental experience in the workforce. 
Hypotheses

As noted above, research has shown that employees typically have more positive reactions to positive feedback than to negative feedback (Bianchi \& Ames, 2008; Kluger and DeNisi, 1996). The notion that positive feedback should result in more positive employee reactions is supported by theory as well. For one thing, it has been suggested that self-ratings of performance are often inflated compared to those of others, indicating that people's impressions of themselves and their performance are generally quite positive (Mabe \& West, 1982). Similarly, Shrauger's selfenhancement theory (1975) suggests that individuals will react more positively to higher ratings, because these ratings are confirming of their already positive selfratings. As a result, I expect to see a main effect of feedback valence such that more positive feedback valence will result in more positive employee feedback reactions. Hypothesis 1: All participants, regardless of age, will report more positive affective, cognitive, and motivational reactions to perceived positive feedback as opposed to perceived negative feedback.

As was also previously noted, research has shown that perceptions of high-quality feedback content have generally positive effects on employee reactions. Moreover, research on informational justice in organizations indicates that employees generally prefer to receive relevant information regarding important organizational events such as formal performance appraisals (Colquitt, 2001; Greenburg, 1993). Thus, I expect 
to see a main effect of feedback content, such that higher quality content will result in more positive employee reactions.

Hypothesis 2: All participants, regardless of age, will report more positive affective, cognitive, and motivational reactions to perceived high-quality feedback content as opposed to perceived low-quality feedback content.

Considerably less research has been conducted on employee reactions to feedback delivery, but recent studies have indicated that more positive delivery generally results in more positive employee reactions to feedback. Bianchi and Ames (2008), for instance, found that higher quality delivery was predictive of more positive affective judgments, trust in the supervisor, and subsequent motivation. This effect was seen regardless of feedback valence, and even regardless of content quality.

Thus, given that delivery has been identified as an important aspect of feedback reactions and that people generally like to be treated fairly and with respect in organizations and in performance appraisal settings according to interpersonal justice literature (Erdogan, 2002; Greenburg, 1993), I expect to see a main effect of feedback delivery such that higher quality delivery will result in more positive employee feedback reactions.

Hypothesis 3: All participants, regardless of age, will report more positive affective, cognitive, and motivational reactions to perceived high-quality feedback delivery as opposed to perceived low-quality feedback delivery. 
The preceding main-effect hypotheses are secondary to the main purpose of this thesis, which is to test age interactions with perceived performance feedback session characteristics. Therefore, the following interaction hypotheses are the primary ones for the study that follows.

Feedback valence has historically been associated with affect and emotion in the feedback reactions literature. Given that SST posits that older adults are more emotionally-focused than younger adults, I expect to see a two-way interaction between age and feedback valence, such that older employees will have more extreme negative reactions to negative feedback and more extreme positive reactions to positive feedback. Specifically, age will moderate the relationship between valence and feedback reactions such that this relationship will be stronger for older adults than for younger adults.

Hypothesis 4: Age and feedback valence will interact such that older participants' affective, cognitive, and motivational reactions will be more dependent on perceived feedback valence than will younger participants' reactions.

SST also posits that younger adults are more information-driven and place greater emphasis on information that will benefit them in the future. The content of performance feedback, referring to the specificity, clarity, and credibility of the feedback, is an important way in which this information can be obtained. The content of a feedback event, if thorough and complete, can inform employees of where their 
strengths and weaknesses are, and how they can improve in the future. Given the relative importance of future opportunities and possibilities for younger adults, one would expect that their perceptions of the quality of feedback content would be significantly more influential on their reactions than on the reactions of older employees. However, all feedback events contain some level of valence, which, as earlier hypothesized, older adults should be more reactive to.

Hypothesis 5: Age, perceived feedback valence, and perceived feedback content quality will interact such that: (a) younger employees perceiving high-quality content will have similarly positive affective, cognitive, and motivational reactions regardless of feedback valence while; (b) younger employees perceiving low-quality content will have similarly negative affective, cognitive, and motivational reactions regardless of feedback valence and; (c) older adults perceiving either high-quality or low-quality content will display similar affective, cognitive, and motivational reaction patterns across these two conditions such that valence will affect their reactions more dramatically than the reactions of the younger employees in both conditions.

In addition, as previously noted, perceptions of feedback delivery have a highly socio-emotional component to them. While all employees generally prefer to be treated well in interpersonal situations as a principle of interpersonal justice (Greenburg, 1993), SST suggests that older adults may place greater importance on 
this feedback component than younger adults, as older individuals are more likely to be focused on emotional regulation and gratifying social relationships. Again, all formal feedback events will contain some level of valence in addition to the component of delivery, and older adults are hypothesized to be reactive to this valence as well.

Hypothesis 6: Age, perceived feedback valence, and perceived feedback delivery quality will interact such that: (a) older participants perceiving high-quality delivery will exhibit more positive affective, cognitive, and motivational reactions than younger adult across feedback valences, despite their more extreme reactions to valence and; (b) older participants perceiving low-quality feedback delivery will exhibit more negative affective, cognitive, and motivational reactions than younger adults across feedback valences, despite their more extreme reactions to valence. 


\section{Method}

Participants and Procedure

Participants were 371 employees from a British subsidiary of an automotive company in China. Although the company is a joint venture with a British organization, this particular organization employs Chinese workers and is located in Shen Zhen, China. The company employs about 500 people, most of whom are engineers or technicians. During the month of February formal performance feedback is administered to each employee for promotion and feedback purposes.

The age of the participants in this sample ranged from 20 to 58; the average age sample was 34.98 years. $65.5 \%$ were under the age of 40 , and could be considered "younger adults" according to the United States Age Discrimination in Employment Act (Department of Labor, 2010). The remaining 34.5\% were over the age of 40 and thus could be considered "older adults". More specifically, 27.2\% of the participants in the sample were in their twenties, $38 \%$ were in their thirties, $32.9 \%$ were in their forties, and $1.9 \%$ were in their fifties. Of the sample, $83 \%$ were male. Participants in the sample had an average of 13.4 years of education. Most were married and had low- to mid-range incomes (between 1000 and 3000 Yuan per month, or approximately 150 to 460 dollars per month).

Participants were administered surveys at two points in time and encouraged to complete the surveys in a private conference room at their workplace. They were asked to provide demographic information regarding themselves as well as their 
immediate supervisors. They were also asked to consider their most recent performance appraisal administered by that supervisor when responding to both surveys. The first wave of surveys concerned respondent perceptions of the feedback event (i.e., their impressions of the valence, content, and delivery quality of the feedback). At this time, participants had been given formal feedback an average of three weeks prior to the survey. Respondents were also asked about the reason for the feedback they were given; they cited a wide range of purposes for their most recent performance appraisal, which included pay/salary, bonus, and promotion. The second wave of surveys concerned respondent reactions to the feedback (i.e., their affective, cognitive, and motivational reactions). At this time the formal feedback had occurred an average of 8.3 weeks prior to the survey. Responses to the first wave of surveys yielded a sample size of 382 participants. Of these, $97 \%$ provided responses to the second wave of surveys. Not surprisingly, the demographic composition of the two waves of participants was nearly identical.

Measures

Valence. Perceptions of feedback valence were assessed using two general judgment items adapted from Bianchi and Ames (2008). One of these items required participants to indicate their general impression of the feedback on a five-point Likert scale ranging from extremely negative overall (a score of one) to extremely positive overall (a score of five). The second item asked participants to indicate their overall judgment and feeling of the feedback event on a five-point Likert scale ranging from 
very bad (a score of one) to very good (a score of five). The item responses were then averaged together to create one valence score. Cronbach's alpha for these items was 0.93 .

Content. Perceptions of feedback content were assessed using an adapted Informational Justice Scale from Colquitt (2001). This five-item scale required participants to indicate the quantity and quality of the information given during the feedback event on a seven-point Likert scale ranging from "strongly disagree" (a response of one) to "strongly agree" (a response of seven). An example of one such item is "My supervisor explained the feedback thoroughly". Responses to the five items were averaged together to create one content score, with higher scores indicating better perceptions of feedback content. Cronbach's alpha for these items was 0.90 .

Delivery. Perceptions of feedback delivery were assessed using an adapted Interpersonal Justice Scale from Colquitt (2001). This four-item scale asked participants to indicate the quality of the treatment they received from their supervisor during the feedback event on a seven-point Likert scale ranging from "strongly disagree" (a score of one) to "strongly agree" (a score of seven). An example of one such item is "My supervisor treated me in a polite manner during the feedback event". Responses to the four items were averaged together to create one delivery score, with responses closer to seven indicating better perceptions of feedback delivery. Cronbach's alpha for these items was 0.85 . 
Affective Reactions. Employee affective reactions to the feedback were measured using a Satisfaction with Appraisal scale created by Dobbins, Cardy, and Platz-Vieno (1990). This twelve-item scale required participants to indicate how they felt about the feedback event on a seven-point Likert scale, with a score of one indicating "strongly disagree" and a score of seven indicating "strongly agree". An example of one of these items is "I am satisfied with my most recent feedback appraisal". One of the items was phrased negatively (e.g., "Based on what I contribute to my company, I am not satisfied with my most recent feedback") and thus was reverse scored and coded. Responses to the twelve items were averaged together to create one satisfaction score, with higher scores indicating greater satisfaction with the appraisal event. Cronbach's alpha for these items was 0.96 .

Employee affective reactions were also measured using employee feedback reaction items adapted from Brett and Atwater (2001). These six items required participants to indicate the extent to which the feedback made them feel a certain way on a Likert scale ranging from one (strongly disagree) to seven (strongly agree). An example of one such item is "The feedback made me feel pleased". Responses to the six items were averaged together to create one affective reaction score, with higher scores indicating better reactions. Cronbach's alpha for these items was 0.89 .

Cognitive Reactions. Employee cognitive reactions were assessed using an adapted Utility of Training scale developed by Ford and Noe (1987). Specifically, the scale was adapted to encompass perceptions of utility of the feedback. This five-item 
measure asked participants to indicate how useful they found the feedback to be on a seven-point Likert scale (again, one indicating "strongly disagree" and seven indicating "strongly agree"). An example item is "The feedback I was given was useful for my development as an employee". Responses to the five items were averaged together to create one cognitive reaction score, with higher scores indicating better cognitive reactions. Cronbach's alpha for these items was 0.97 .

Employee cognitive reactions were additionally measured using employee feedback reaction items adapted from Brett and Atwater (2001). These six items required respondents to indicate the degree to which they thought a certain way about the feedback event on a Likert scale ranging from one (strongly disagree) to seven (strongly agree). An example item is "The feedback made me feel aware". Responses to the six items were averaged together to create one average cognitive reactions score, with higher scores indicating better cognitive reactions. Cronbach's alpha for these items was 0.90 .

Motivational Reactions. Employee motivational reactions were measured using four items from Bianchi and Ames (2008). These items required participants to indicate how motivated they felt at work as a result of the feedback event (as opposed to in general). The items were scored on a seven-point Likert scale ranging from one (very negative impact) to seven (very positive impact); an example of one such item is "My desire to improve my performance". For each item, participants were asked to indicate what kind of impact the feedback had on a different motivational aspect. 
Responses to the four items were averaged to create one motivation score, with higher scores indicating greater motivation as a result of the feedback event. Cronbach's alpha for these items was 0.96 .

Employee motivational reactions were also measured using employee feedback reactions items adapted from Brett and Atwater (2001). These four items required respondents to indicate how motivated they felt following the feedback event on a Likert scale ranging from one (strongly disagree) to seven (strongly agree). An example item is "The feedback made me feel encouraged". Responses to the four items were averaged together to create one motivational reaction score, with higher scores indicating better motivational reactions. Cronbach's alpha for these items was 0.86 .

One final way employee motivational reactions were assessed was using an adapted Academic Motivation Scale developed by Wolf and Smith (1995). These four items again required respondents to indicate how motivated they were following the feedback event on a Likert scale ranging from one (strongly disagree) to seven (strongly agree). An example of one such item is, "Doing well in my job is important to me" (respondents were specifically asked to indicate the degree to which they felt this way as a direct result of the feedback event). Responses to the four items were averaged together to create one motivational reaction score, with higher scores indicating better motivational reactions. Cronbach's alpha for these items was 0.90 . 
Control variables. In order to assess the relationship between employees and their supervisors, the LMX-8 scale developed by Bauer and Green (1996) was used. These eight items were scored on a seven-point Likert scale, with a response of one indicating "strongly disagree" and a response of seven indicating "strongly agree". An example item is "My supervisor understands my problems and needs"; responses to the eight items were averaged and higher scores indicated a better relationship between the respondent and his or her supervisor. In the instructions participants were asked to consider the relationship in general, and not interactions in their most recent performance appraisal. This scale was administered in both waves of surveys. Any variation in LMX reported by participants at these two time points was not significant, $t(368)=1.37, p=0.17$.

In addition, participants were asked to indicate their supervisor's gender and approximate age as part of the demographic information collected, as well as gender congruence (i.e., whether they were the same gender as their supervisor) and elements of supervisor familiarity (how long they had been working with their current supervisor that delivered the feedback, and how many times that supervisor had delivered formal performance feedback to them prior to this experience). Thus, these measures of supervisor-employee relationship, supervisor characteristics, similarity and familiarity were included in the analyses to determine the effects of the independent variables over and above their own potential predictive effects on the feedback reaction outcomes. 
Results

Descriptive analyses were conducted for each variable and to determine means and frequencies of demographic information. Reliabilities for each scale used were calculated using Cronbach's method (Cronbach, 1951). In order to determine which scales would best represent participant reactions to the feedback, several confirmatory factor analyses were conducted. First, three separate single-factor CFAs were conducted in order to determine which items best represented affective, cognitive, and motivational reactions, respectively. The first analysis revealed that the items comprising the Satisfaction with Appraisal Scale yielded the highest regression weights and the best fit with the fewest missing participant data points, $X^{2}(54)=$ $337.3, \mathrm{p}<0.01, \mathrm{CFI}=0.94, \mathrm{RMSEA}=0.12$. The second analysis revealed that the items comprising the adapted Utility of Training Scale yielded the highest regression weights and the best fit with the fewest missing participant data points, $X^{2}(5)=95.8$, $\mathrm{p}<0.01, \mathrm{CFI}=0.96, \mathrm{RMSEA}=0.22$. Finally, the third single-factor CFA revealed that the items comprising Bianchi and Ames' Motivational Reactions yielded the highest regression weights and the best fit with the fewest missing participant data points, $X^{2}(2)=38.1, \mathrm{p}<0.01, \mathrm{CFI}=0.98, \mathrm{RMSEA}=0.22$. The three outcome variables reported (Satisfaction with Appraisal, Utility of Feedback, and Motivational Reactions) provided the best fit for a three-factor model, $X^{2}(187)=1105.11, \mathrm{p}<$ $0.01, \mathrm{CFI}=0.91, \mathrm{RMSEA}=0.12$ (in comparison, a three-factor model using Brett and Atwater's (2001) reaction items resulted in the following fit indices: $X^{2}(102)=$ 
1092, $\mathrm{p}<0.01, \mathrm{CFI}=0.81, \mathrm{RMSEA}=0.16)$. As was previously mentioned, these three scales contained the fewest missing data points and thus allowed us to remove the fewest number of participants. Thus, the Satisfaction with Appraisal scale (Dobbins et al., 1990), the Utility of Feedback scale (adapted from Ford \& Noe, 1987) and the Motivational Reactions scale (Bianchi \& Ames, 2008) respectively represent employee affective, cognitive, and motivational reactions to feedback in the current study. Seventeen of the respondents were removed from the analyses, as they did not completely fill out the surveys and left missing data for essential variables. The removal of these participants did not significantly change the demographic composition of the sample. A total of 354 participants provided useable data for analyses.

Hierarchical multiple regression analyses were conducted in order to determine whether feedback valence, informational justice (or content), and interpersonal justice (or delivery) and the interactions of these variables with employee age significantly predicted employee affective, cognitive, and motivational reactions to the feedback. These three types of reactions were considered separately; three regression analyses were conducted. Significance of these variables and the interactions among them were determined jointly by their corresponding regression coefficients and the significance of the change in $R$ square of the corresponding step in the analysis.

The analyses were conducted in an a priori manner to allow for all relationships among the variables of interest to be seen. As such, each regression analysis consisted 
of five steps. In the first step, the standardized control variables of supervisor age, supervisor gender, how long the employee had worked with the supervisor, how many times that supervisor had delivered formal performance feedback to the employee in the past, the LMX relationship between the employee and that supervisor, and supervisor-employee gender congruence were entered. In the second step, all standardized main effects (age, valence, informational justice or content, and interpersonal justice or delivery) were entered. In the third step, all possible two-way interactions among the independent variables were standardized, pre-calculated, and entered into the regression analysis. This step consisted of a total of six two-way interactions. In the fourth step all possible three-way interactions, standardized and pre-calculated, were entered for a total of four three-way interactions in the regression analysis. In the fifth and final step of the regression, the four-way interaction between the four independent variables (age, valence, content, and delivery) was precalculated based on the standardized values of the variables and entered into the equation.

For each of the three outcomes, the averages of the scores for the scale items were used, with scores closer to one indicating very poor reactions and scores closer to seven indicating very good reactions. In line with recent literature (Bianchi \& Ames, 2008; Brett \& Atwater, 2001), the three reaction types were highly correlated. Their inter-correlations can be seen in Table 1. All interactions were graphed by plotting the calculated expected values of the outcome variables using one standard deviation 
above and below the means of the standardized independent variables in the interaction.

\section{Table 1}

Pearson correlations among Affective, Cognitive, and Motivational Reaction Scales

\begin{tabular}{|lllc|}
\hline & 1 & 2 & 3 \\
\hline 1) Sat w App & 1.0 & $.80^{* * *}$ & $.74^{* *}$ \\
$\begin{array}{l}\text { 2) Utility of } \\
\text { Feedback }\end{array}$ & $.80^{* * *}$ & 1.0 & $.73^{* *}$ \\
$\begin{array}{l}\text { 3) Motivational } \\
\text { Reactions }\end{array}$ & $.74^{* *}$ & $.73^{* *}$ & 1.0 \\
\hline$* *$ Significant at the 0.01 level & & \\
\hline
\end{tabular}

Descriptive Results

Satisfaction with appraisal. Overall, participants seemed generally satisfied with their performance appraisals. The mean satisfaction score for all 354 participants who gave useable data was 5.25. The standard deviation of these ratings was 1.21. Many of the independent variables, in particular feedback valence $(r=0.55, p<0.01)$, content (informational justice; $r=0.47, p<0.01$ ), and delivery (interpersonal justice; $r=0.46, p<0.01$, were strongly correlated with satisfaction. Additionally, some of the control variables, such as LMX $(r=0.44, p<0.01)$, were also strongly correlated with employee satisfaction with the feedback. 
Perceived utility of feedback. Participants in this sample generally found the feedback events in question to be useful. Mean ratings for utility were 5.47, while the standard deviation for these ratings was 1.42. Again, valence, content and delivery proved to be strongly correlated with utility ratings $(r=0.34, p<0.01 ; r=0.36, p<$ 0.01 ; and $r=0.37, p<0.01$, respectively). Additionally, control variables such as supervisor age $(r=0.09, p<0.05)$, supervisor gender $(r=0.10, p<0.05)$, and LMX $(r=0.33, p<0.01)$ were significantly correlated with utility ratings.

Motivational reactions. Overall, participants in this sample were fairly motivated by the feedback they were given. The mean for motivation ratings was 5.56; the standard deviation was 1.25 . Feedback valence, content, and delivery were all significantly correlated with motivational reactions $(r=0.41, p<0.01 ; r=0.34, p<$ 0.01 ; and $r=0.35, p<0.01$, respectively), as were supervisor age $(r=0.12, p<0.05)$, supervisor gender $(r=0.10, p<0.05)$, supervisor-employee gender congruence $(r=-$ $0.12, p<0.05)$, and $\operatorname{LMX}(r=0.32, p<0.01)$

In addition, several of the independent variables were intercorrelated. Informational and interpersonal justice were strongly related, $r=0.65, p<0.01$, as were valence and informational justice $(r=0.50, p<0.01)$ and valence and interpersonal justice $(r=0.39, p<0.01)$. LMX was strongly correlated with valence $(r=0.38, p<0.01)$, informational justice $(r=0.62, p<0.01)$, and interpersonal justice $(r=0.63, p<0.01)$, while the number of times the supervisor had delivered feedback was strongly correlated with ratings of informational justice $(r=0.14, p<$ 
0.01). Not surprisingly, supervisor tenure was related to the number of times the supervisor had delivered feedback in the past $(r=0.34, p<0.01)$, as was employee age $(r=0.39, p<0.01)$. LMX was associated with higher supervisor age $(r=0.15, p$ $<0.01)$.

\section{Model Summaries}

Satisfaction with appraisal. In this regression, the $R$ square change was significant for steps 1,2 , and 3 , indicating that the control variables together significantly predicted satisfaction with appraisal $(F(6,347)=14.67, p<0.01)$, as did the independent variables $(F(4,343)=31.48, p<0.01)$ and the two-way interactions among the independent variables $(F(6,337)=2.56, p=0.02)$. Step 4 , however, did not produce a significant change in $R$ square $(F(4,333)=1.36, p=0.25)$, indicating no significant predictive value of the three-way interactions among the independent variables over and above the preceding steps. Step 5 showed a significant change in $R$ square $(F(1,332)=7.24, p=0.01)$ indicating that the four-way interaction between age, valence, content, and delivery was predictive of satisfaction with appraisal over and above the preceding steps.

Perceived utility of feedback. In this regression, the $R$ square change was significant for steps 1,2 , and 3 , indicating that the control variables together significantly predicted satisfaction with appraisal $(F(6,347)=10.57, p<0.01)$, as did the independent variables $(F(4,343)=20.21, p<0.01)$ and the two-way interactions among the independent variables $(F(6,337)=2.45, p=0.03)$. Step 4 , however, did 
not produce a significant change in $R$ square $(F(4,333)=1.79, p=0.13)$, indicating no significant predictive value of the three-way interactions among the independent variables over and above the preceding steps. Step 5 showed a marginally significant increase in $R$ square $(F(1,332)=3.81, p=0.05)$ indicating that the four-way interaction between age, valence, content, and delivery was marginally predictive of employee perceptions of feedback utility over and above the preceding steps.

Motivational reactions. In this regression, the $R$ square change was significant for steps 1 and 2, indicating that the control variables together significantly predicted satisfaction with appraisal $(F(6,347)=8.29, p<0.01)$, as did the independent variables $(F(4,343)=13.63, p<0.01)$. However, step 3 showed only a marginally significant increase in $R$ square $(F(6,337)=2.01, p=0.06)$, indicating that the twoway interactions together were only marginally predictive of employee motivational reactions when the control and independent variables had already been taken into account. Step 4 did not produce a significant change in $R$ square $(F(4,333)=0.86, p$ $=0.49$ ), indicating no significant predictive value of the three-way interactions among the independent variables over and above the preceding steps. Step 5 also did not show a significant increase in $R$ square $(F(1,332)=1.26, p=0.26)$ indicating no predictive value of the four-way interaction between age, valence, content, and delivery for motivational reactions over and above the preceding steps. 
Hypothesis 1 Results

A summary of all supported and unsupported hypotheses can be found in Table 2. Hypothesis 1 suggested a positive relationship between feedback valence and employee reactions.

Satisfaction with appraisal. The multiple regression analysis yielded support for Hypothesis 1, in that standardized feedback valence significantly and positively predicted how satisfied employees were with their most recent performance appraisals, $B=0.53, t=7.69, p<0.01$.

Perceived utility of feedback. This analysis yielded support for Hypothesis 1, in that standardized feedback valence significantly and positively predicted how useful employees perceived their most recent performance appraisals to be, $B=0.51, t=$ $5.90, p<0.01$

Motivational reactions. This analysis also yielded support for Hypothesis 1, in that standardized feedback valence significantly and positively predicted how motivated employees were following their most recent performance appraisal, $B=$ $0.36, t=4.47, p<0.01$.

Hypothesis 2 Results

Hypothesis 2 suggested a positive relationship between feedback content (or feedback-specific informational justice) and employee reactions. 
Satisfaction with appraisal. This multiple regression analysis did not yield support for Hypothesis 2. Specifically, feedback content quality was not found to significantly predict satisfaction, $B=0.11, t=1.31, p=0.19$.

Perceived utility of feedback. This analysis also did not yield support for Hypothesis 2 in that feedback content quality was not found to significantly predict perceptions of utility, $B=0.02, t=0.23, p=0.82$.

Motivational reactions. This analysis did not yield support for Hypothesis 2; perceived feedback content quality was not significantly predictive of post-feedback motivation, $B=-0.01, t=-0.12, p=0.91$.

Hypothesis 3 Results

In Hypothesis 3, it was suggested that there would be a positive relationship between the perceived quality of feedback delivery (or feedback-specific interpersonal justice) and employee reactions to the feedback.

Satisfaction with appraisal. This analysis yielded support for Hypothesis 3; there was a significant positive relationship between perceived delivery quality and employee satisfaction of the feedback event after a time lag $(B=0.25, t=3.18, p<$ $0.01)$.

Perceived utility of feedback. This analysis yielded support for Hypothesis 3; there was a significant positive relationship between perceived delivery quality and employee perceptions of how useful the feedback was $(B=0.31, t=3.067, p<0.01)$. 
Motivational reactions. This analysis also yielded support for Hypothesis 3; there was a significant positive relationship between perceived delivery quality and how motivated employees felt by the feedback $(B=0.23, t=2.50, p=0.01)$. Hypothesis 4 Results

In Hypothesis 4, it was suggested that a two-way interaction would be seen for employee age and perceived feedback valence, such that older adults would have more extreme positive reactions to positive valence and more extreme negative reactions to perceived negative valence.

Satisfaction with appraisal. This analysis revealed support for Hypothesis 4. The age by valence interaction was significant, $B=0.27, t=3.57, p<0.01$, and revealed a stronger slope for older adults depending on differences in perceived feedback valence than for younger adults. This relationship can be seen in Figure 1.

Figure 1

Age by Valence Interaction: Satisfaction with Appraisal as outcome

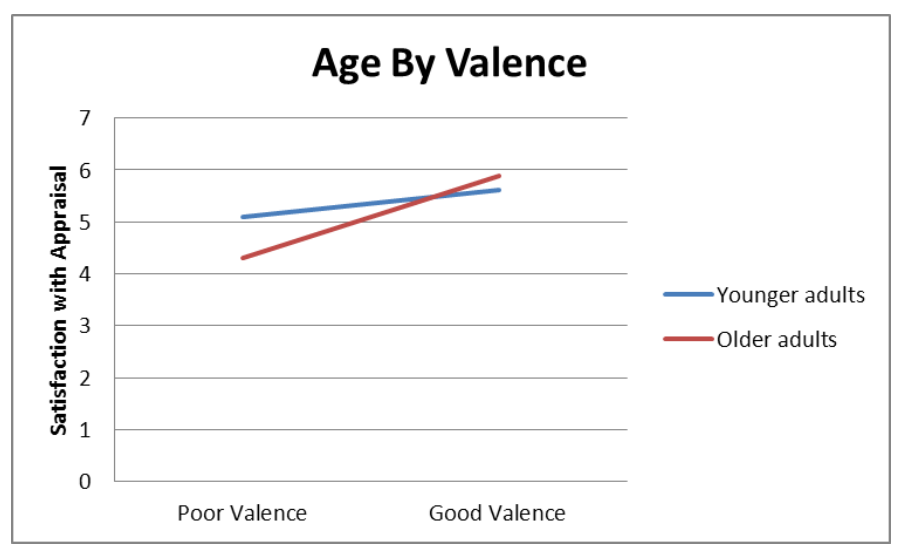


Perceived utility of feedback. This analysis revealed marginal support for Hypothesis 4 . The age by valence interaction was marginally significant, $B=0.19, t=$ $1.96, p=0.05$ and revealed a slightly stronger slope for older adults depending on differences in perceived feedback valence than for younger adults. This relationship can be examined in Figure 2.

Figure 2

Age by Valence Interaction: Utility of Feedback as outcome

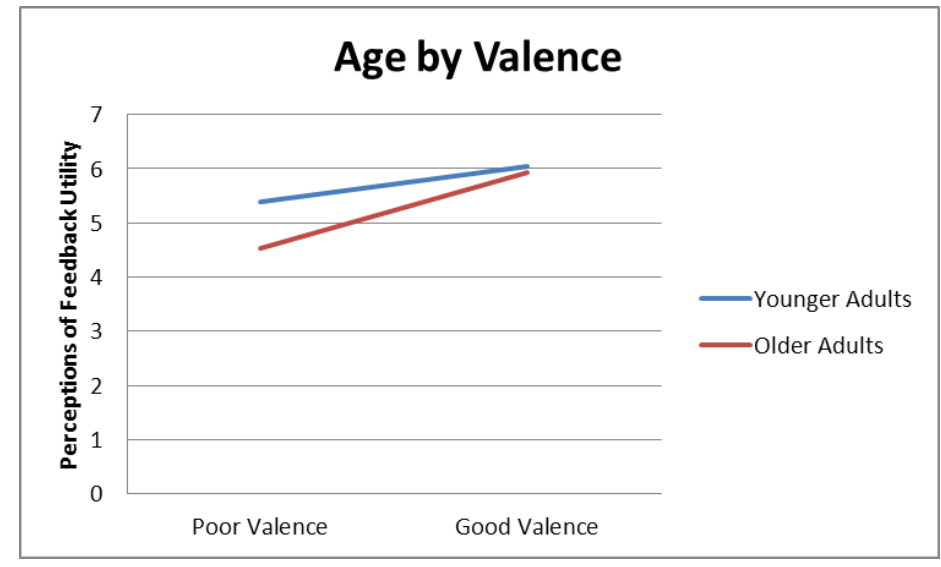

Motivational reactions. This analysis also revealed marginal support for hypothesis $4(B=0.17, t=1.96, p=0.05)$, showing a slightly stronger slope for older adults depending on differences in perceived feedback valence than for younger adults. This relationship can be examined in Figure 3 . 
Figure 3

Age by Valence Interaction: Motivational Reactions as outcome

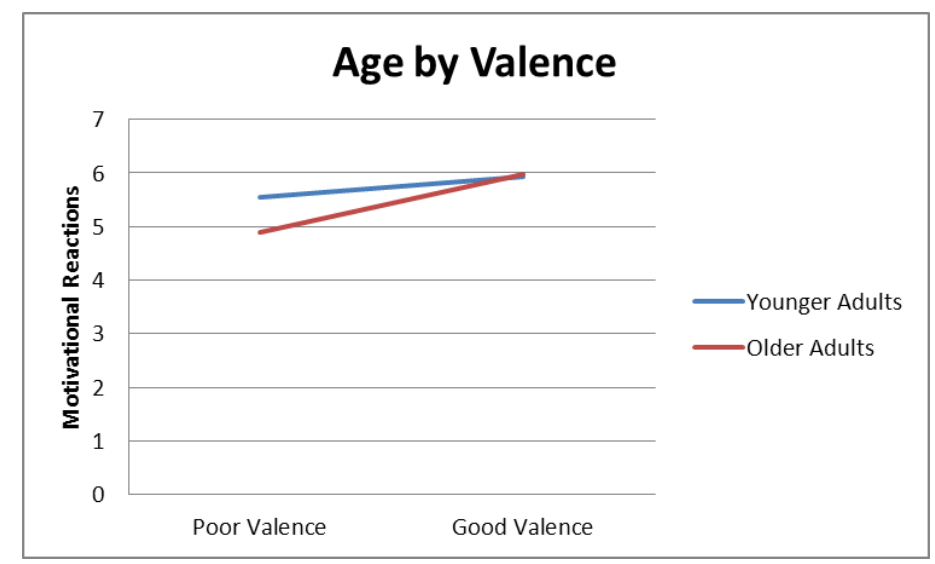

Hypothesis 5 Results

In Hypothesis 5, a three-way interaction between employee age, perceived valence, and perceived content quality (or feedback-specific informational justice) was proposed such that younger adults' reactions would be more impacted by content quality while older adults would remain unimpacted by content quality and would remain impacted by feedback valence, as per Hypothesis 4 .

Satisfaction with appraisal. This analysis did not yield support for Hypothesis 5; the three-way interaction between employee age, feedback valence, and feedback content did not approach significance $(B=-0.02, t=-0.26, p=0.80)$. 
Perceived utility of feedback. This analysis also did not yield support for Hypothesis 5; the three-way interaction between employee age, feedback valence, and feedback content did not approach significance $(B=0.06, t=0.64, p=0.52)$.

Motivational reactions. This analysis did not reveal support for Hypothesis 5; the three-way interaction between employee age, feedback valence, and feedback content did not approach significance $(B=-0.02, t=-0.25, p=0.80)$.

\section{Hypothesis 6 Results}

In Hypothesis 6 it was suggested that employee age, perceived feedback valence, and perceived feedback delivery quality (or feedback-specific interpersonal justice) would interact such that older adults would experience more marked reactions to both feedback delivery and feedback valence simultaneously than would younger adults.

Satisfaction with appraisal. The three-way interaction between age, valence, and delivery quality was significant, $B=0.22, t=2.47, p=0.01$. Plots of this interaction revealed that younger adults' satisfaction relied more on valence when delivery quality was poor, while older adults' satisfaction was more dependent on valence when delivery quality was good. This relationship can be seen in Figures $4 \mathrm{a}$ and $\mathrm{b}$. 
Figures $4 \mathrm{a}$ and $4 \mathrm{~b}$

Age by Valence by Delivery Interaction: Satisfaction with Appraisal as outcome
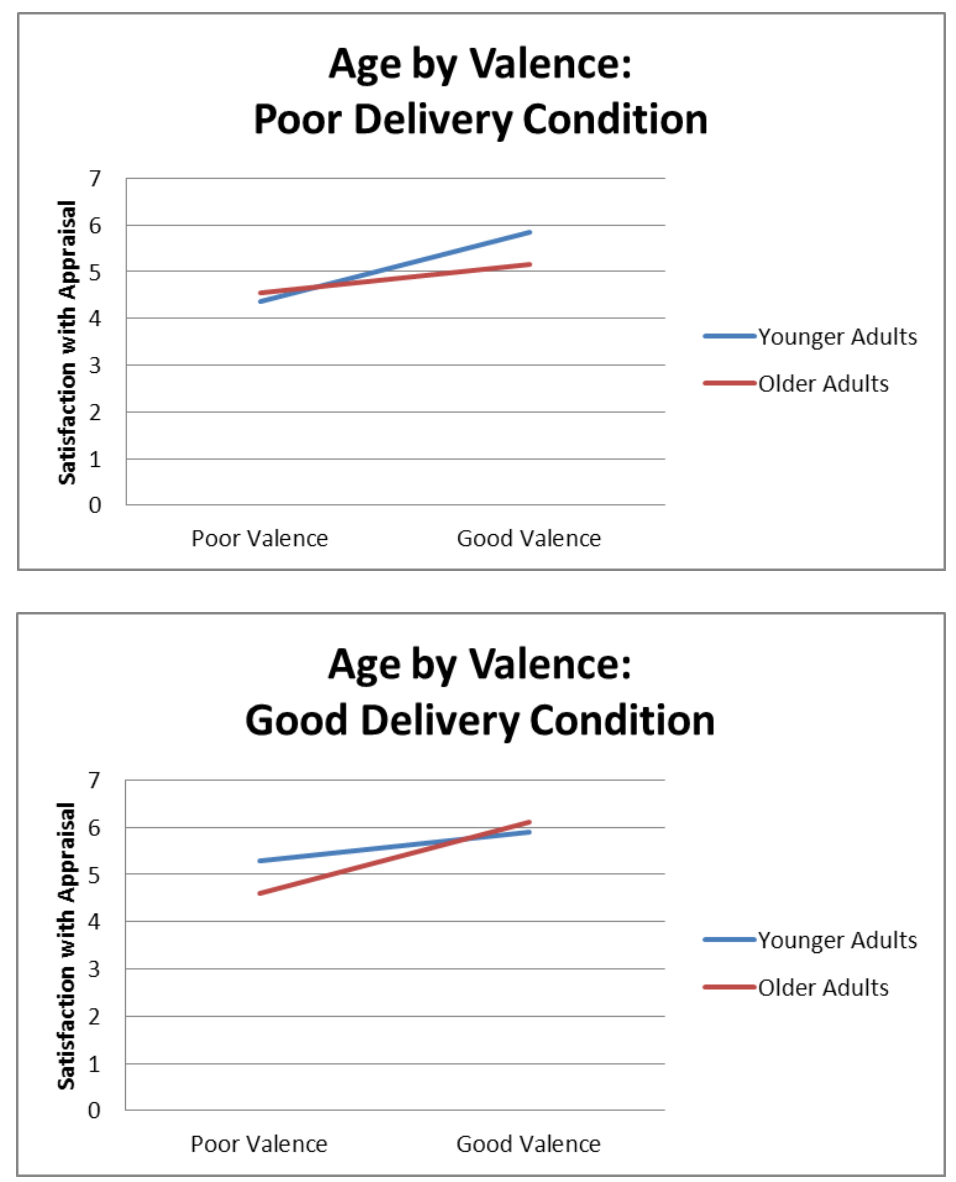

Perceived utility of feedback. The three-way interaction between age, valence, and delivery quality was significant, $B=0.25, t=2.21, p=0.03$. This relationship can be more closely examined in Figures $5 \mathrm{a}$ and $\mathrm{b}$. These figures jointly reveal that the nature of the interaction is similar to the significant three-way interaction between age, valence, and delivery on the satisfaction ratings mentioned above. Specifically, 
younger adults' utility perceptions were more reliant on valence when delivery quality was poor, while older adults' utility perceptions were more reliant on valence when delivery quality was good.

Figures $5 \mathrm{a}$ and $5 \mathrm{~b}$

Age by Valence by Delivery Interaction: Utility of Feedback as outcome
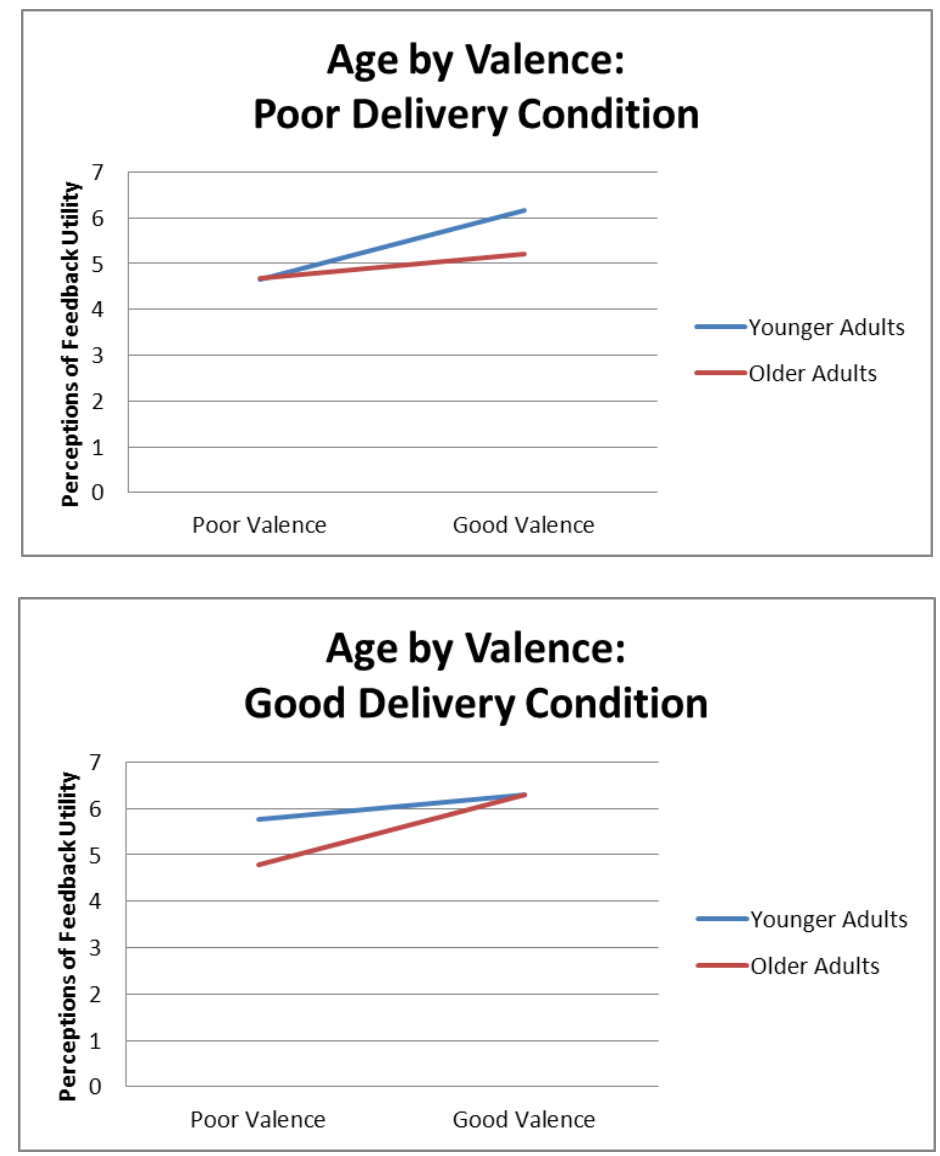
Motivational reactions. This analysis did not yield support for Hypothesis 6; the three-way interaction between age, valence, and delivery quality did not reach significance with this outcome $(B=0.17, t=1.57, p=0.12)$.

Table 2

Hypothesis Support

\begin{tabular}{|c|c|c|c|}
\hline & $\begin{array}{l}\text { Satisfaction } \\
\text { with } \\
\text { Appraisal }\end{array}$ & $\begin{array}{l}\text { Utility of } \\
\text { Feedback }\end{array}$ & $\begin{array}{l}\text { Motivational } \\
\text { Reactions }\end{array}$ \\
\hline Hyp 1: Valence & Supported & Supported & Supported \\
\hline Hyp 2: Content & No support & No support & No support \\
\hline Hyp 3: Delivery & Supported & Supported & Supported \\
\hline 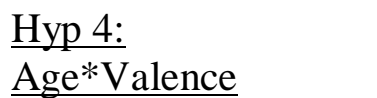 & Supported & $\begin{array}{l}\text { Marginally } \\
\text { supported }\end{array}$ & $\begin{array}{l}\text { Marginally } \\
\text { supported }\end{array}$ \\
\hline $\begin{array}{l}\text { Hyp 5: } \\
\text { Age*Valence*Cont }\end{array}$ & $\begin{array}{l}\text { a) No support } \\
\text { b) No support } \\
\text { c) No support }\end{array}$ & $\begin{array}{l}\text { No support } \\
\text { No support } \\
\text { No support }\end{array}$ & $\begin{array}{l}\text { No support } \\
\text { No support } \\
\text { No support }\end{array}$ \\
\hline $\begin{array}{l}\text { Hyp } \\
\text { 6:Age*Valence*Deliv }\end{array}$ & $\begin{array}{l}\text { a) No support } \\
\text { b) Supported, } \\
\text { partially }\end{array}$ & No support & No support \\
\hline
\end{tabular}




\section{Exploratory Analyses}

In addition to the hypothesis tests, the hierarchical multiple regression analyses allowed for other possible main-effect and interaction effects to be examined as significant predictors of employee reactions to performance feedback.

Significant control variables. LMX was a significant predictor of whether or not people were satisfied with the feedback event $(B=0.16, t=2.13, p=0.03)$.

The number of times the supervisor had delivered feedback in the past was a marginally significant negative predictor of satisfaction, $B=-0.09, t=-1.72, p=0.09$, such that people were slightly more satisfied with the appraisal when it came from someone who had delivered feedback to them fewer times in the past.

Additionally, age was marginally significant in negatively predicting satisfaction $(B=-0.12, t=-1.83, p=0.07)$, significant in negatively predicting feedback utility perceptions $(B=-0.24, t=-2.79, p<0.01)$, and marginally significant in negatively predicting post-feedback employee motivation $(B=-0.15, t=-1.92, p=0.06)$.

Supervisor-employee gender congruence was negatively predictive of feedback utility $(B=-0.22, t=-3.38, p<0.01)$ such that participants perceived feedback as being more useful when it came from someone of the opposite gender. Similarly, employee-supervisor gender congruence was marginally predictive of motivation ( $B$ $=-0.11, t=-1.77, p=0.08)$ such that participants were more motivated when the feedback came from a supervisor of a different gender.

Significant two-way interactions. Age by content. The two-way interaction between age and content was a marginally significant predictor of employee 
perceptions of the utility of the feedback, $B=-0.19, t=-1.89, p=0.06$. This

relationship can be more closely examined in Figure 6; younger adults had

considerably higher utility perceptions to high quality content while older adults'

utility perceptions actually decreased as the quality of feedback content went up. A

simple slope analysis revealed that the relationship for older adults observed in this interaction was marginally significant, $B=-0.19, p=0.06$.

Figure 6

Age by Content Interaction: Utility of Feedback as outcome

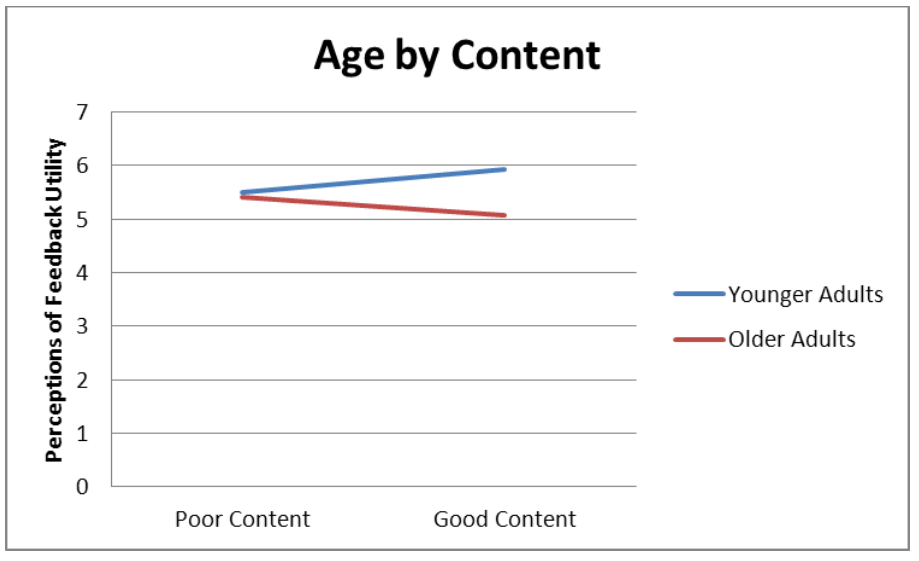

The two-way interaction between age and content was also marginally significant in predicting motivational reactions $(B=-0.17, t=-1.78, p=0.08)$ such that younger adults had more positive reactions to better quality content, while older adults had more negative reactions to better quality content (see Figure 7). A simple slope 
analysis revealed that the relationship for older adults observed in this interaction was marginally significant, $B=-0.17, p=0.08$.

Figure 7

Age by Content Interaction: Motivational Reactions as outcome

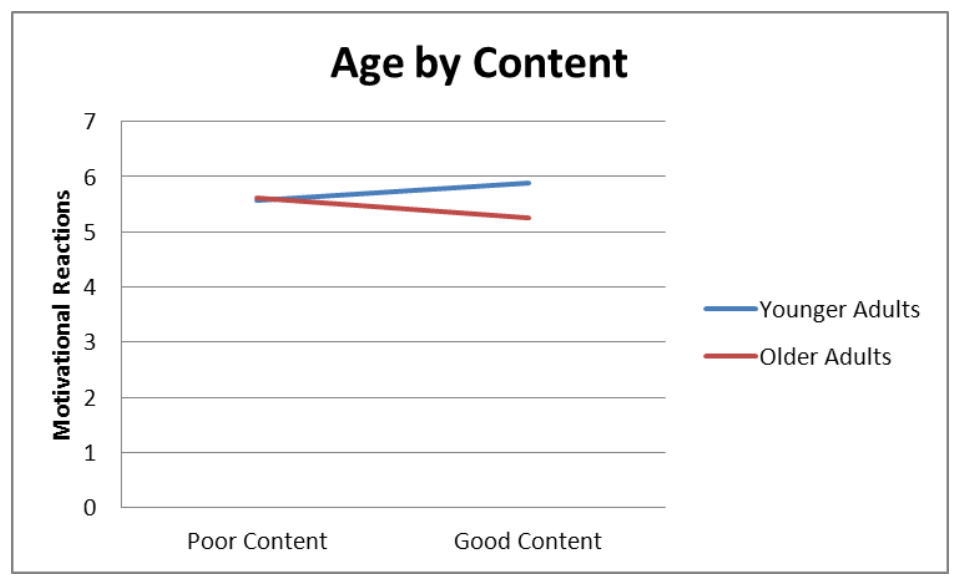

Age by delivery. The two-way interaction between age and delivery was a significant predictor of employee utility perceptions $(B=0.30, t=2.98, p<0.01)$, such that older adults' utility perceptions were more strongly affected by delivery quality (see Figure 8). 
Figure 8

Age by Delivery Interaction: Utility of Feedback as outcome

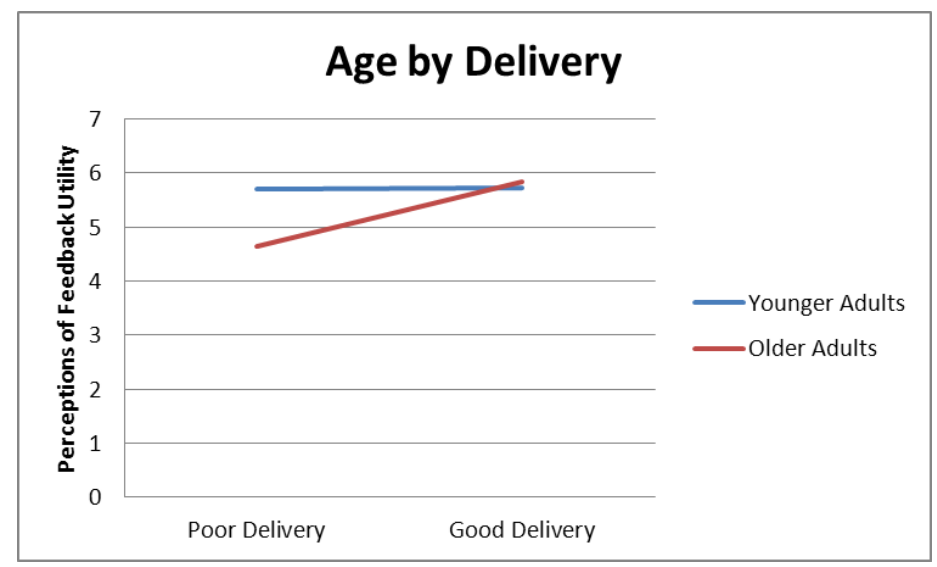

The two-way interaction between age and delivery was also significant in predicting employee motivational reactions $(B=0.22, t=2.42, p=0.02)$ such that older adults' post-feedback motivation was more strongly affected by delivery than that of younger adults (see Figure 9). 
Figure 9

Age by Delivery Interaction: Motivational Reactions as outcome

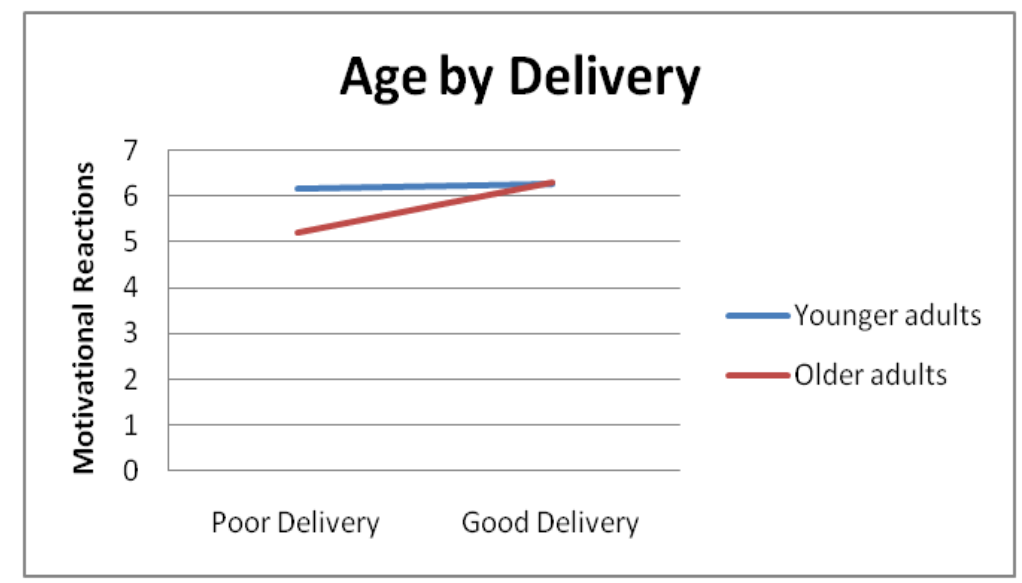

Valence by delivery. The two-way interaction between valence and delivery was a significant predictor of appraisal satisfaction $(B=0.15, t=2.20, p=0.03)$ such that good feedback valence yielded even greater satisfaction when feedback delivery was perceived as being good as well (see Figure 10). 
Figure 10

Valence by Delivery Interaction: Satisfaction with Appraisal as outcome

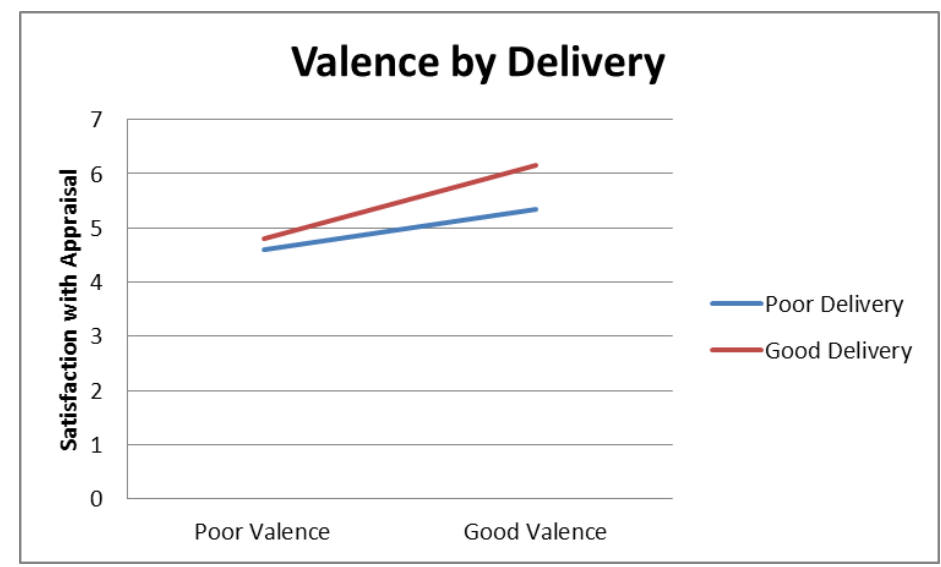

The two-way interaction between valence and delivery was marginally significant in predicting employee cognitive reactions to feedback $(B=0.16, t=1.75, p=0.08)$, such that participants found feedback that was high in valence to be marginally more useful when delivery quality was high (see Figure 11). 
Figure 11

Valence by Delivery interaction: Utility of Feedback as outcome

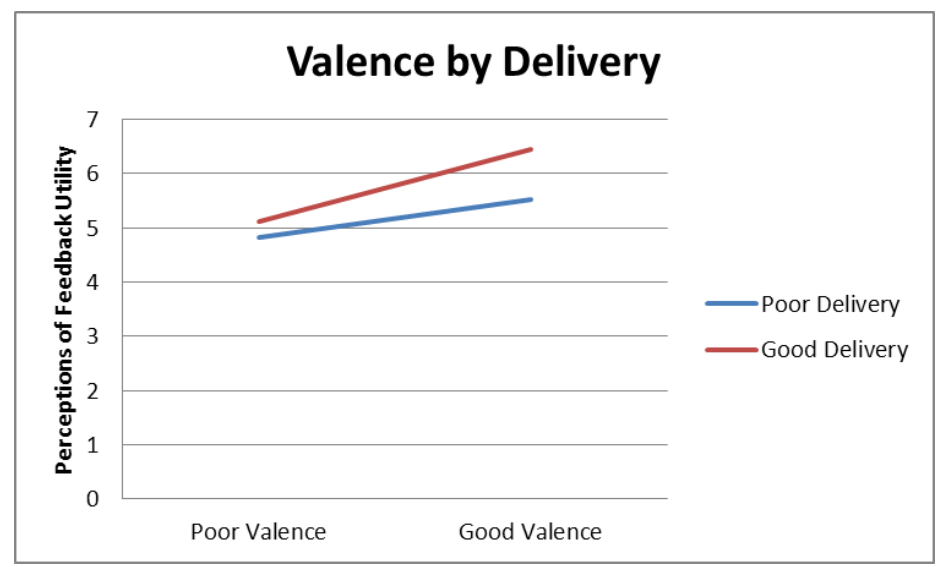

Similarly, the two-way interaction between valence and delivery was a significant predictor of motivational reactions $(B=0.17, t=2.02, p=0.04)$ such that feedback that was positively valenced was even more motivating when the delivery quality was high as well (see Figure 12). 
Figure 12

Valence by Delivery Interaction: Motivational Reactions as outcome

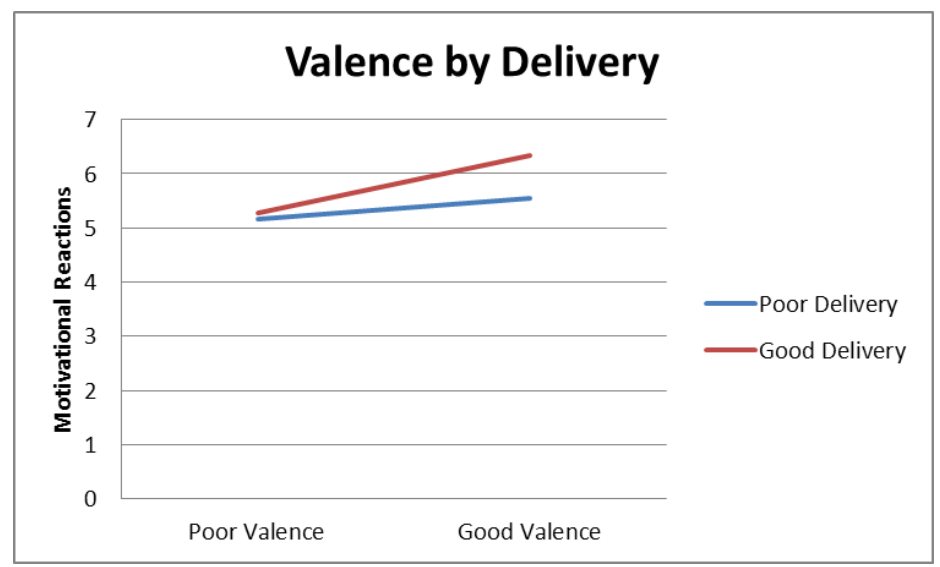

Significant three-way interactions. Age by content by delivery. Although it was not included in the hypotheses, the three-way interaction between age, perceived content quality, and perceived delivery quality was marginally significant in predicting satisfaction with appraisal, $B=-0.15, t=-1.90, p=0.06$. The nature of this interaction was such that when content quality was perceived as being poor, older adults' satisfaction depended more heavily on delivery quality. When content quality was perceived as being good, younger adults' satisfaction depended more heavily on delivery quality. This relationship can be more closely examined in Figures 13a and b. 
Figures $13 \mathrm{a}$ and $13 \mathrm{~b}$

Age by Content by Delivery Interaction: Satisfaction with Appraisal as outcome
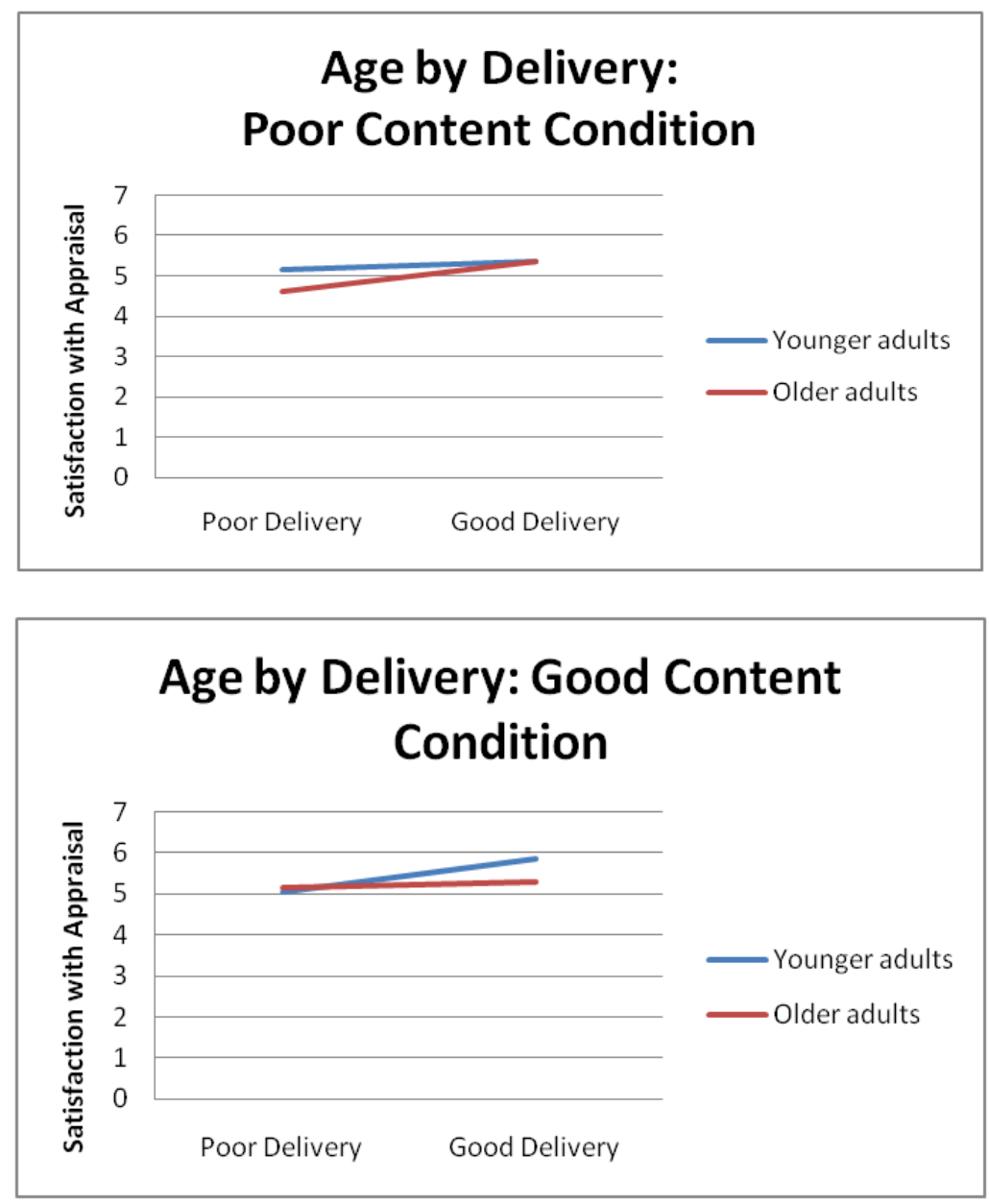

The three-way interaction between age, content, and delivery was a significant predictor of perceptions of feedback utility, $B=-0.20, t=-1.99, p<0.05$. Similar to the marginally significant relationship with satisfaction, the nature of this interaction was such that lower quality content resulted in older adults' utility perceptions being more dependent on delivery quality, while higher quality content resulted in younger 
adults' utility perceptions being more dependent on delivery quality. This relationship can be more closely examined in Figures $14 \mathrm{a}$ and $\mathrm{b}$.

Figures $14 \mathrm{a}$ and $14 \mathrm{~b}$

Age by Content by Delivery Interaction: Utility of Feedback as outcome
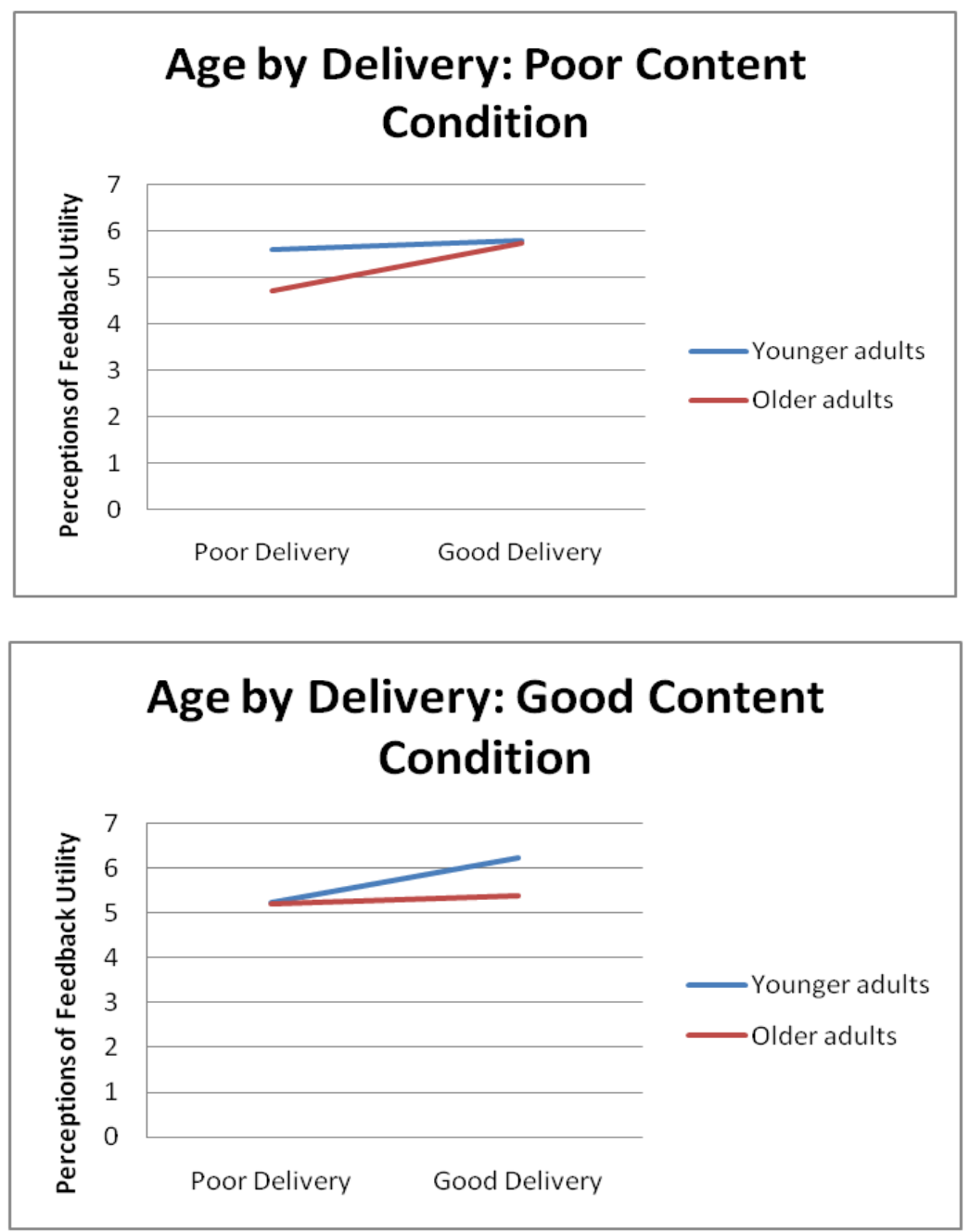
Significant four-way interaction. The four-way interaction between employee age, perceived valence, perceived content quality, and perceived delivery quality was significant in predicting employee satisfaction with appraisal, $B=-0.16, t=-2.69, p<$ 0.01. This interaction, as can be seen in Figures 15a, b, c, and d was such that the interactive effects of delivery quality (good or bad) and content quality (good or bad) reversed between younger and older workers depending on whether feedback valence was positive or negative. That is, younger adults receiving negative feedback were generally more satisfied with good feedback delivery regardless of the quality of the feedback content (see Figure 15a), while older adults receiving negative feedback were more satisfied with both high-quality feedback content and delivery (see Figure 15c). Conversely, younger adults receiving positive feedback were more satisfied when this feedback came with good content and delivery (see Figure 15b), while older adults receiving positive feedback were more satisfied with good feedback delivery regardless of the quality of content (see Figure 15d). 
Figures $15 \mathrm{a}, 15 \mathrm{~b}, 15 \mathrm{c}$, and $15 \mathrm{~d}$

Age by Valence by Content by Delivery Interaction: Satisfaction with Appraisal as outcome

Younger Adults (15a and 15b)
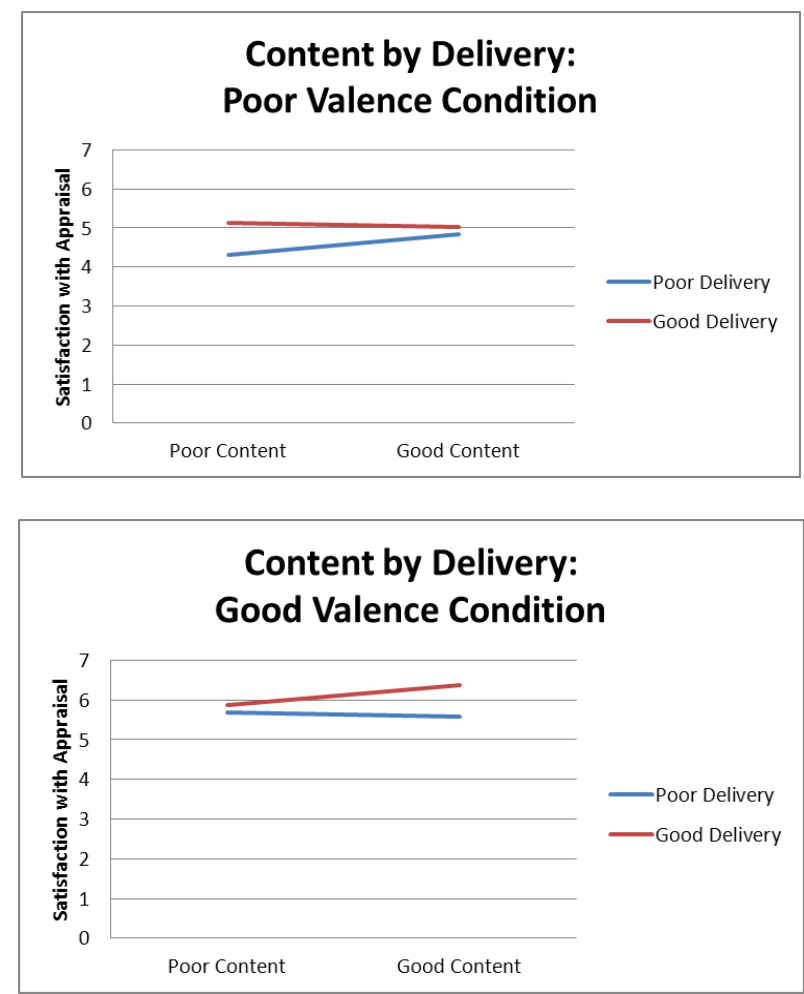
Older Adults (15c and 15d)
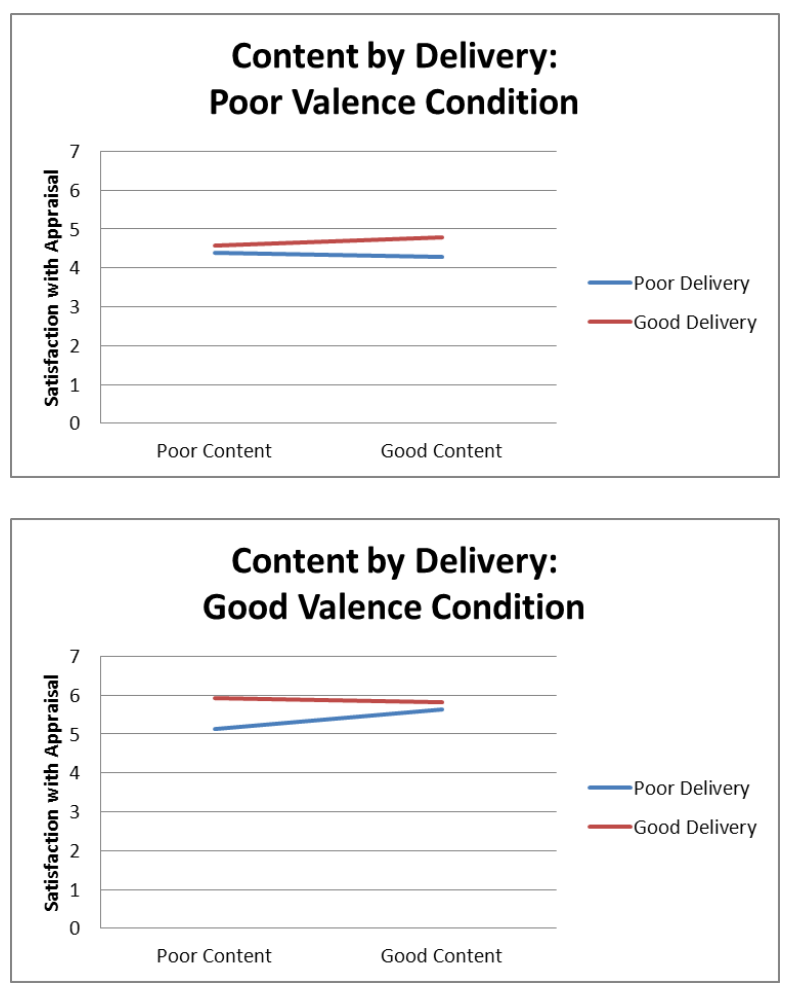

The four-way interaction was marginally significant in predicting employee perceptions of feedback utility, $B=-0.15, t=-1.95, p=0.05$. This relationship can be more closely examined in Figures 16a, b, c, and d. The nature of this interaction was similar to the one mentioned above; younger adults receiving negative feedback found good delivery to be more useful, regardless of content quality (see Figure 16a); older adults receiving negative feedback found it to be most useful when it was accompanied by both high-quality content and delivery (see Figure 16c). Younger adults receiving positive feedback found feedback that was high in content and delivery quality to be the most useful (see Figure 16b); older adults receiving positive 
feedback found high-quality delivery to be useful but not high-quality content (see

Figure 16d).

Figures 16a, 16b, 16c, and 16d

Age by Valence by Content by Delivery Interaction: Utility of Feedback as outcome

Younger Adults (16a and 16b)
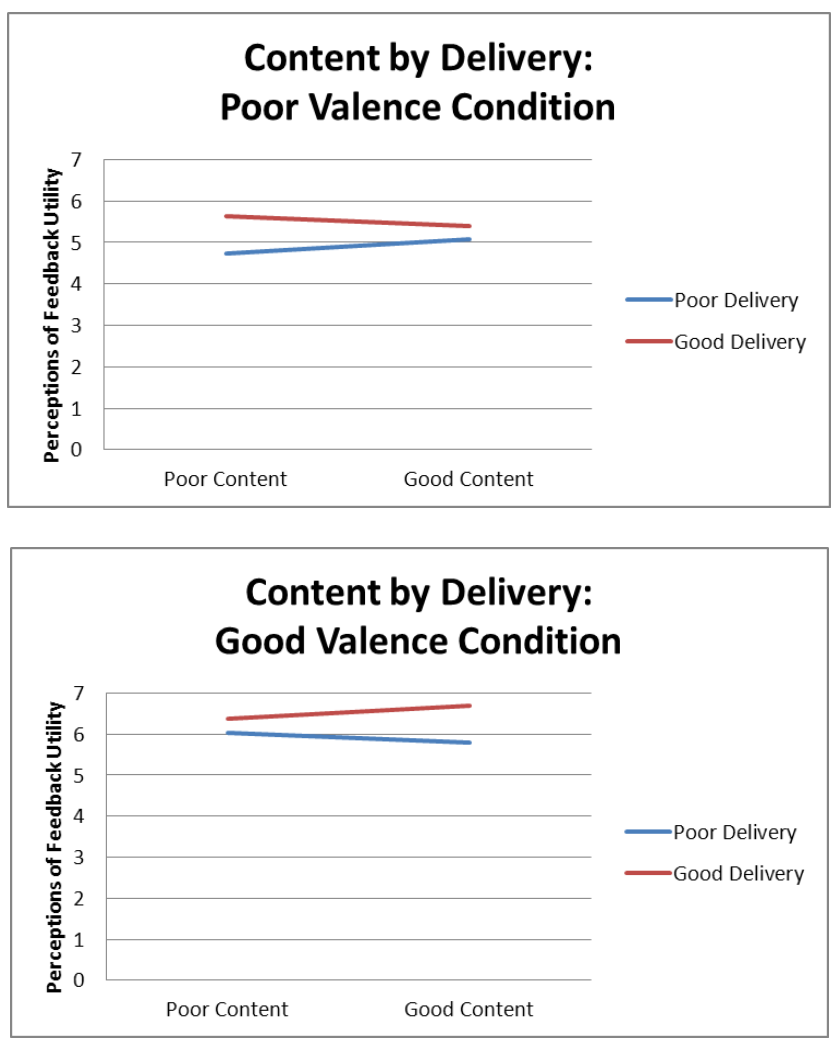
Older Adults (16c and 16d)
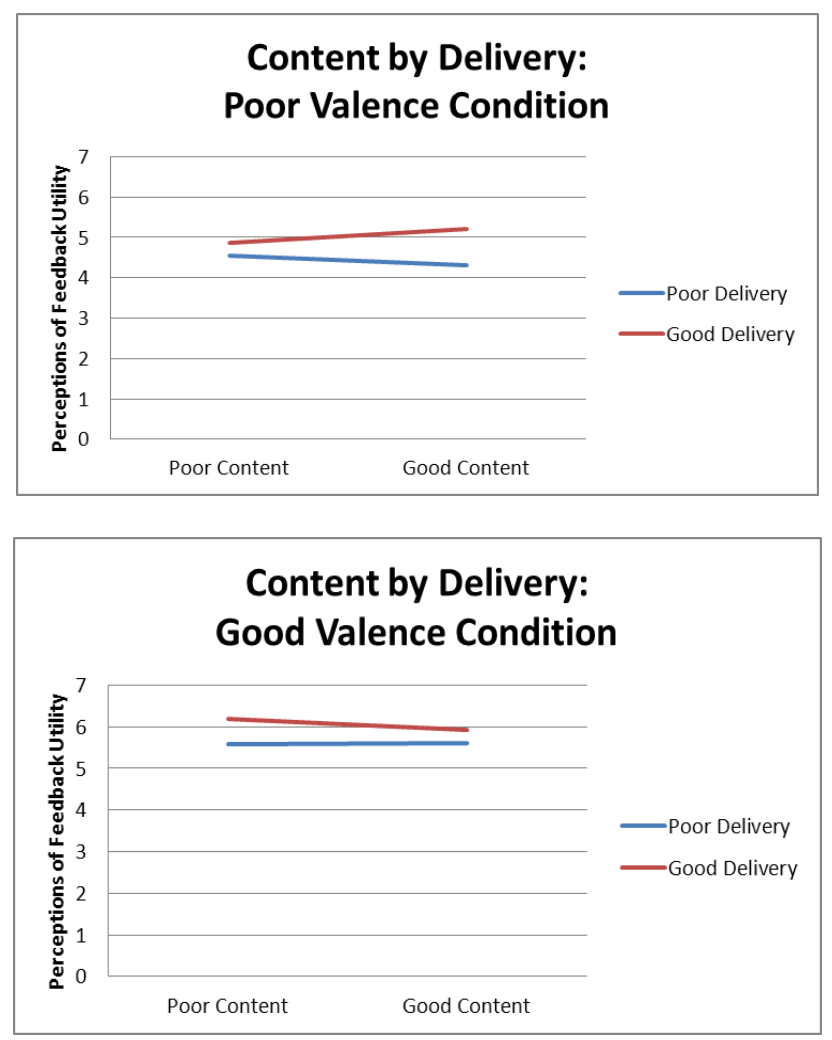

Analyses run without controlling for LMX

As a control variable, LMX was highly correlated with each of the outcome variables and there was some concern about conceptual overlap with the outcomes. Specifically, because SST is so focused on social relationships, it may be incomplete to consider feedback reactions by themselves without considering the simultaneous impact that LMX may have on these reactions. For this reason the three regression analyses were re-run without LMX to see what changes, if any, the exclusion of this variable produced. 
Many of the same relationships were still observed in terms of predicting satisfaction with appraisal. Age was a marginally negative predictor, $\mathrm{B}=-0.13, \mathrm{p}=$ 0.06; valence was a positive predictor, $\mathrm{B}=0.53, \mathrm{p}<0.01$, delivery was a positive predictor, $\mathrm{B}=0.30, \mathrm{p}<0.01$; age by valence was a significant interaction, $\mathrm{B}=0.27$, $\mathrm{p}<0.01$; and valence by delivery was a significant interaction, $\mathrm{B}=0.17, \mathrm{p}=0.02$. Additionally, the three-way interaction between age, valence, and delivery was still significant, $\mathrm{B}=0.22, \mathrm{p}=0.01$. The four-way interaction between age, valence, content, and delivery remained a significant predictor, $B=-0.17, p<0.01$. However, without controlling for LMX, content became a significant positive predictor of satisfaction with appraisal, $B=0.17, p=0.03$. The three-way interaction between age, content, and delivery quality lost some of its predictive power in this condition, $B=-$ $0.13, p=0.10$.

Similarly, the predictors for perceived utility of feedback changed very little when LMX was not controlled. Gender congruence again negatively predicted utility perceptions, $B=-0.22, p<0.01$; Age was again a negative predictor, $B=-0.24$, $p<0.01$; valence and delivery were again positive predictors, $B=0.52, p<0.01$ and $B=0.35, p<0.01$, respectively; age by valence was a significant interaction, $\mathrm{B}=$ $0.19, \mathrm{p}<0.05$; age by delivery was a significant interaction, $B=0.28, p<0.01$; and valence by delivery was marginally significant, $B=0.17, p=0.06$. Additionally, the three-way interaction between age, valence, and delivery was again significant, $B=$ $0.25, p=0.03$. The four-way interaction between age, valence, content, and delivery gained some predictive power in this condition, $B=-0.15, p=0.04$. The age by 
content interaction lost some of its predictive power without the inclusion of LMX $(B=-0.16, p=0.10)$, as did the three-way interaction between age, content, and delivery $(B=-0.18, p=0.07)$.

Positive predictors of Motivational Reactions were also roughly the same whether LMX was included as a control variable or not. Gender congruence was a marginally significant predictor of post-feedback motivation, $B=-0.11, p=0.08$; age was a marginally significant negative predictor, $B=-0.15, p=0.05$; valence and delivery were again positive predictors, $B=0.37, p<0.01$ and $B=0.27, p<0.01$, respectively; age by valence was again a significant predictor, $B=0.18, p<0.05$; age by delivery was a significant interaction, $B=0.21, p=0.03$; and valence by delivery was again a significant interaction, $B=0.18, p=0.03$. The age by content interaction lost some of its predictive power without the inclusion of LMX, $B=-0.14, p=0.13$. 


\section{Discussion}

Across all three types of reactions that were examined, the sample in the current study showed at least some evidence of age differences in the perceptions of and reactions to various facets of a feedback event. Thus, these results suggest that there is some benefit to studying age differences in terms of important human resource management functions; employees of different ages appear to view feedback events that are similar in valence, content, and delivery differently. Additionally, the current analyses revealed that while affective, cognitive, and motivational reactions had similar predictors, they also appeared to be distinct dimensions. Affective and cognitive reactions, for instance, revealed a significant pattern in which older adults' reactions were more affected by feedback valence in the condition of high-quality delivery, while younger adults' reactions were more affected by valence in the condition of low-quality delivery. Motivational reactions, however, showed no such predictive pattern.

The distinctiveness of these reactions suggests that supervisors may attend to different elements of feedback when attempting to channel different types of reactions from their employees. For instance, if job satisfaction has been lacking in a particular organization, supervisors may want to tailor the formal feedback they give to employees of all ages to improve their satisfaction with the appraisal process. Similarly, if motivation is a problem within a given work group, the supervisor can deliver feedback in a way that emphasizes polite and prepared delivery, particularly to older adults. In general, these results imply that supervisors wishing to deliver 
feedback that is maximally efficient and effective can and should consider employee age differences in how they communicate the feedback, and also consider what kinds of reactions are most important for them to elicit in these employees at the time of the performance appraisal. Additionally, while researchers have typically lumped these three types of reactions together into one "reactions" outcome (e.g. Bianchi \& Ames, 2008), these results suggest there is some benefit to examining these constructs separately.

Main Effects of Valence, Content Quality, and Delivery Quality

One unexpected finding was that while feedback valence and delivery quality were predictive of employee affective, cognitive, and motivational reactions to the feedback, content quality was not. These results are inconsistent with past studies which have found all three of these feedback components to be predictive of employee reactions (Bianchi \& Ames, 2008; Brett \& Atwater, 2001). A critical difference between the current study and past studies assessing employee reactions to feedback is the time lag. The second wave of data collection in the current study occurred an average of eight weeks after the formal feedback events in question. Thus, these results suggest that over time, people tend to forget how they felt about the information presented in the feedback event. Alternatively, the case may not be that employees actually forget about feedback content, but that content quality simply does not have a strong predictive effect on reactions over time (this is supported by the fact that informational justice was still significantly correlated with each type of reaction after the eight week lag). However, valence and delivery quality remained 
strong in peoples' memories and reactions to the feedback even after a time lag. Generally supervisors cannot do anything about the valence of a feedback event; hopefully this is a function of employee performance. However, these results do suggest that when aiming to satisfy and motivate employees over a longer period of time, supervisors would be wise to consider the importance of their delivery quality when administering formal performance feedback. Additionally, these results have interesting implications for organizational justice theory. While research has suggested that both informational and interpersonal justice are important in the workplace (Colquitt et al., 2001; Greenburg, 1990; 1993), these findings suggest that interpersonal justice may have an edge in certain workplace events in forming employee reactions over time.

Additionally, these findings make explicit the implicit role of time in employee feedback reactions. As was mentioned in the introduction of this paper, most feedback reactions studies have employed a cross-sectional design in which respondents were asked to indicate their impressions of and reactions to a formal performance appraisal event all at one time (generally the most recent performance appraisal they had received). These results suggest that such an approach may not allow us to see the whole story. Reactions do appear to change over time, and this is likely to affect both feedback impressions and performance as it subsequently relates to the feedback that was given. It is particularly important that we better understand these dynamic relationships, as many organizations administer performance feedback as rarely as annually. Increased knowledge of how these reactions change over time 
will allow us to better understand the longevity of the effects of feedback and feedback reactions. Future researchers may examine the effects of time more explicitly by assessing how feedback impressions and reactions transform and manifest themselves throughout the entire range of time that occurs between formal performance appraisal events.

The Age by Valence Interaction

The proposed age by valence interaction received at least marginal support for all three types of feedback reactions. In each of these interactions, older adults' reactions were more strongly affected by whether they perceived the feedback as being positive or negative, as opposed to younger adults, whose reactions were more resilient to feedback valence. This is consistent both with the proposed hypothesis and with Socio-emotional Selectivity Theory. The older adults in the current sample reacted emotionally, cognitively, and motivationally to variations in feedback valence, while younger adults did so to a much lesser extent. While SST suggests that feedback valence is often regarded emotionally, these findings show that these emotional reactions spill over into other types of reactions as well following a feedback event. They also suggest that older adults are particularly sensitive to feedback valence, so supervisors should be especially mindful of this when delivering performance feedback to older subordinates. The following findings that are presented suggest that there are other elements of the feedback event that supervisors can focus on to offset this effect. 
The Age by Valence by Delivery Interaction

The regression step in which the possible three-way interactions were entered did not show significant predictive utility over the other three steps for any of the reaction types (see tables 5, 6, and 7), and few of the hypothesized three-way interactions were found to approach significance. This may be an artifact of the sample size; three-way interactions typically need a very large sample size for their effects to be powerful enough to be seen (Aiken \& West, 1991; McClelland \& Judd, 1993). However, for both affective and cognitive reactions, one hypothesized three-way interaction came up as a significant predictor, providing us with some interesting information regarding how older and younger adults might respond differently to delivery quality depending on feedback valence. Contrary to hypotheses, older adults did not have better reactions than younger adults to better feedback delivery. They did display worse reactions when feedback delivery was poor, but again contrary to hypotheses in this condition their reactions were not more dependent on feedback valence than were younger adults' reactions. The current analyses revealed that when feedback delivery was poor, younger adults were significantly more satisfied with positive feedback rather than negative feedback. They also found positive feedback to be significantly more useful in this condition. Older adults, however, were more resilient to feedback valence; when feedback delivery was poor, they had similar negative reactions whether valence was positive or negative. This effect changed when feedback delivery was good. In this condition, younger adults had similarly positive affective 
and cognitive reactions whether feedback valence was positive or negative. However, now older adults' reactions were more strongly affected by valence: older adults had much more positive affective and cognitive reactions to positive valence than to negative valence in this condition.

A different way to examine these relationships can be seen in figures $17 \mathrm{a}$ and $\mathrm{b}$ and $18 \mathrm{a}$ and $\mathrm{b}$. These figures provide another interesting portrait of how older and younger employees perceive feedback: when feedback is negative, valence is more important than delivery in determining how satisfied older adults are with the feedback, and how useful they find it to be. When feedback is positive, delivery is more important than valence in determining how satisfied older adults are with the feedback, and how useful they find it to be. The reverse is seen with younger adults: delivery is more important to them when feedback is negatively valenced. 
Figures $17 \mathrm{a}$ and $17 \mathrm{~b}$

Age by Valence by Delivery Interaction: Satisfaction with Appraisal as outcome
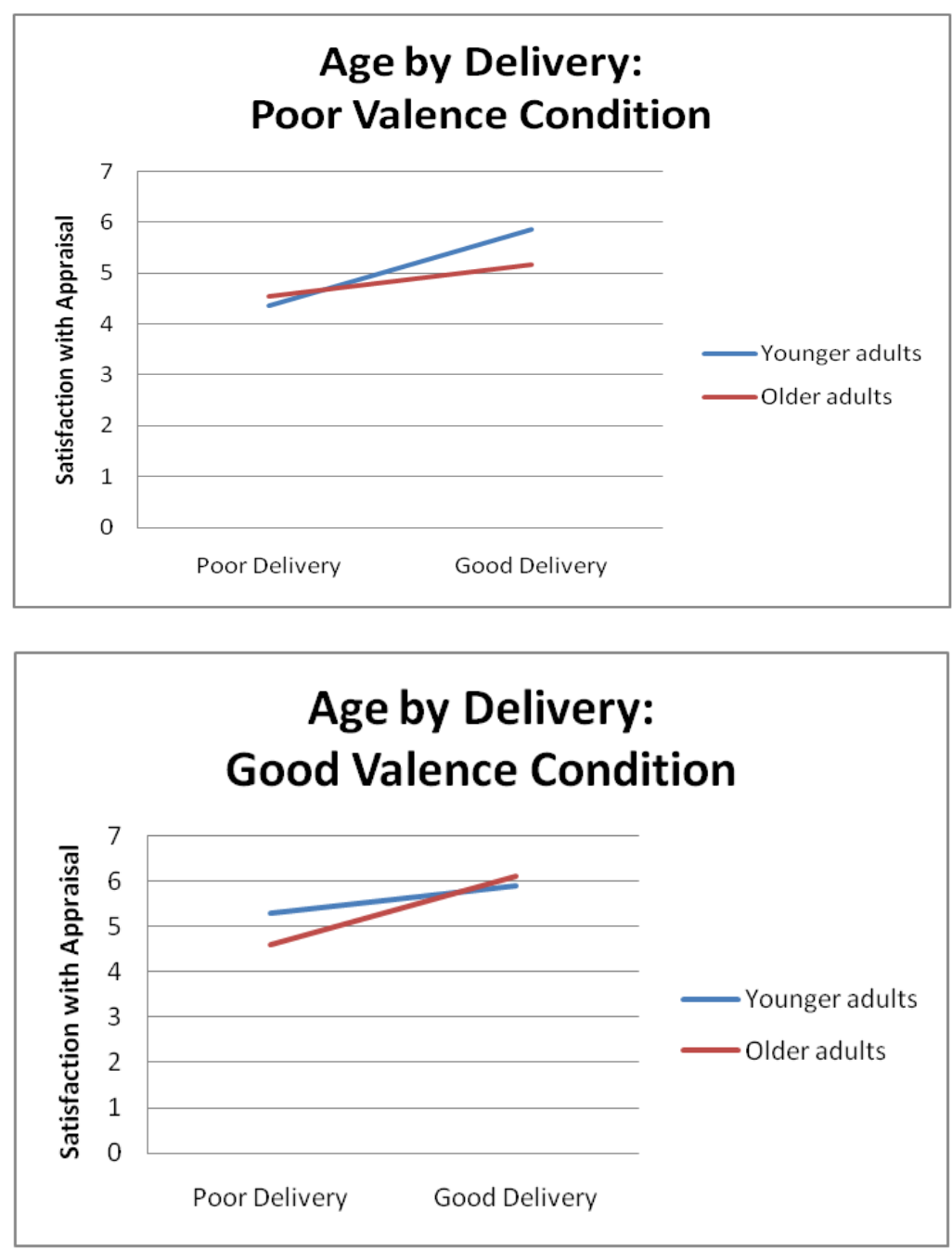
Figures $18 \mathrm{a}$ and $18 \mathrm{~b}$

Age by Valence by Delivery Interaction: Utility of Feedback as outcome
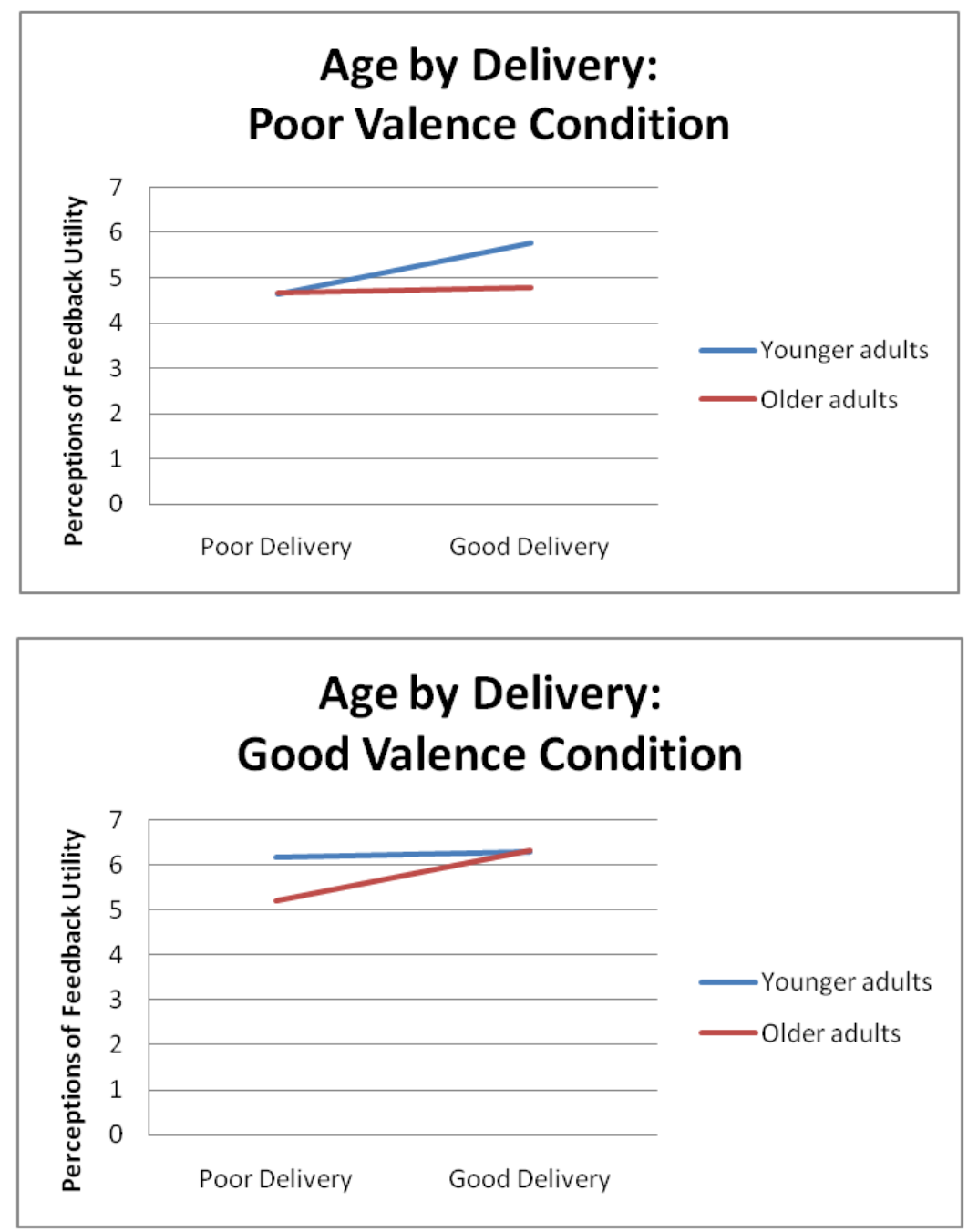

From the standpoint of Socio-emotional Selectivity Theory, this makes sense. It may be that negative feedback indicates to younger adults that they are doing poorly in terms of workplace performance, but positive delivery in this condition indicates that they are still a valued member of the work team and may be given opportunities 
to improve in the future. Thus they find this both satisfying and useful. When feedback is positive, however, this indicates that they are doing well in terms of performance and thus should be met with opportunities in the future, regardless of the quality of the supervisor's delivery. SST is a bit more difficult to tie into the reactions of older adults. It may be that negative valence is such an emotional event that older adults feel and think negatively about the feedback regardless of other feedback elements. However, when feedback is positive, they are more satisfied and encouraged by delivery that indicates a good relationship with one's supervisor. Thus, delivery becomes important to them in this condition, because positive valence by itself is not enough to convey the quality of this relationship. This is consistent with Socio-emotional Selectivity studies that have suggested that older adults may especially attend to negative information in the short-term (Carstensen \& Mikels, 2005). If feedback is positive but delivery is low-quality, there is still something negative going on in this condition that could be causing the reduced affective and cognitive reactions we see with older adults.

\section{Exploratory Analyses: Main Effects}

Although these effects were beyond the main scope of the study, the findings regarding the control variables provided some interesting insight to how demographic and social dynamics between employees and supervisors affect employee perceptions of and reactions to formal performance feedback. LMX, for instance, positively predicted how satisfied people of all ages were with the feedback, but not how useful they found it or how motivated they felt by it. Thus, it appears that some of the 
emotional components of the LMX relationship carry over to impact affective reactions to feedback. Along these lines, conducting a regression analysis without controlling for LMX revealed support for perceived content quality as a significant predictor of employee satisfaction, whereas controlling for LMX masked this relationship. It appears that over time, employees may attribute the quality of content that was presented to them in a performance appraisal setting to the quality of the relationship between themselves and their supervisors, and this manifests itself affectively. Conducting the regression analyses with and without LMX revealed some interesting patterns regarding its relationship as a construct with content: not including LMX as a control decreased the predictive power of many of the interactions involving content for all three types of reaction outcomes (for instance, the two-way interaction between age and content became insignificant in predicting both cognitive and motivational reactions). Future researchers may want to further investigate the link between LMX and employee desire for content-rich feedback, as the two appear to be linked in the workplace.

Employee-supervisor gender congruence was a significant predictor of how useful participants found the feedback to be, and marginally predictive of how motivated participants felt following the feedback. However, both of these relationships were negative, such that greater gender congruence resulted in reduced utility perceptions and motivational reactions. Thus, in this sample, male employees typically felt that feedback was more useful and motivating coming from female supervisors, and vice versa. This relationship is a bit unclear, given that there were relatively few female 
supervisors in the sample. Additionally, gender roles in China may impact this relationship and may not directly generalize to other nations (Chen \& Francesco, 2000; Lai, 1995; Schein, Mueller, Lituchy, \& Liu, 1996). Nevertheless, these results provide further evidence that demographic and social dynamics between employees and their supervisors impact how employees perceive and react to information coming from their supervisors, and these variables need to be taken into account when examining employee reactions to supervisor-led human resource practices. Research has suggested that employees who are similar to supervisors in demographic aspects tend to be better liked and glean better relationships with those supervisors (Lefkowitz, 2000; Tsui \& O’Reilly, 1989), but very few researchers have undertaken the task of examining these relationships in the context of performance appraisals. These results suggest that supervisor-employee demographic patters need to be further studied relative to performance appraisals. Additional research in the area of relational demography as it pertains to business practices and values crossnationally and cross-culturally should be conducted as well.

One interesting thing to note is that across reaction types, age was found to be at least a marginal negative predictor. Thus, older adults typically had lower affective, cognitive, and motivational reactions to feedback than younger adults, regardless of feedback valence, content, and delivery quality. This is consistent with literature suggesting that younger adults place greater emphasis on feedback in general. Specifically, several researchers have suggested that younger adults comprise a generational cohort that is in need of reassurance and performance feedback in the 
workplace, and that their satisfaction and efficacy depends on it (Deal, 2006;

Kupperschmidt, 2000). Older adults, by contrast, tend to place less emphasis on performance feedback in general, and thus the view these events as being generally less important and have reduced affective, cognitive, and motivational reactions as a result. This actually may support some of the tenets of Socio-emotional Selectivity Theory. One argument is that younger adults, craving greater employability and opportunities to improve, value feedback so much because it provides them with concrete information regarding how they are performing and how they can improve. It is possible that older adults place less emphasis on these feedback events because they are simply less concerned with improving and growing as an employee (Deal, 2006).

Exploratory analyses: Two-way interactions

When examining unhypothesized significant interactions in the regression analyses, we begin to see an interesting picture of how employee age interacts with elements of the feedback event to produce various employee reactions to the feedback.

For both cognitive and motivational reactions, the two-way interaction of age and content was marginally significant. This relationship displayed similar patterns across reaction types: younger adults found feedback that was high in content quality to be more useful and motivating. This is consistent with SST: better content provides people with specific information of how they can improve and grow as employees. Older adults' reactions, by contrast, were found to be slightly more resilient to 
content quality, but their reactions actually decreased as content quality got better. Specifically, older adults tended to perceive feedback with high-quality content as being less useful and motivating. It may be that older adults simply value the feedback event less in general, and the extra time that it takes for a supervisor to deliver pertinent career-related information may be less useful to them. Conversely, it may be that older adults have negative reactions to hearing about specific, credible ways that their performance could improve, and this emotional reaction spills over to the other types of feedback reactions as well. These mechanisms are simply suggestions; excluding the notion that older adults are less interested in performance feedback in general (Deal, 2006) researchers have yet to assess why older adults may experience more negative cognitive and motivational reactions to feedback content quality. While content is a critical part of a feedback episode, supervisors might consider the fact that older adults won't necessarily react well to better content when administering feedback to their older employees, particularly if they are trying to garner certain employee reactions over time. Researchers may want to use both qualitative and quantitative methods in the future to assess why this effect is being seen.

The two-way interaction between age and delivery was a significant predictor of utility perceptions and motivational reactions. Specifically, delivery quality impacted older adults' perceptions of the feedback event being useful and motivating, much more so than younger adults, whose cognitive and motivational reactions were more or less resilient to delivery quality. Thus, when delivery was poor, older adults were 
more likely to rate the feedback as being useless and non-motivating. However, when delivery quality was high, older adults found the feedback to be both more useful and more motivating. This is consistent with SST: I hypothesized that delivery would be more important to older adults. Delivery indicates both the level of respect a supervisor has for an employee, and the quality of the relationship between the employee and that supervisor (Bianchi \& Ames, 2008). Thus, according to SST, older adults should be more concerned with this element of the feedback event. Interestingly, this interaction was not a significant predictor of satisfaction with the appraisal event. Thus, both older and younger adults had similar affective reactions to delivery quality, but older adults' cognitive and motivational reactions were markedly more affected by this. As a tenet of SST one would expect that older adults' emotional reactions to a feedback event should be impacted by perceived delivery quality, but that was not the case with this sample. One possibility is that older participants did experience an emotional reaction to delivery quality, but this manifested itself through their perceptions of utility and motivation following the feedback event (certainly the three types of reactions examined were strongly correlated). However, it is also possible that SST does not provide us with the theoretical backing to explain this relationship. Perhaps employees of all ages experience similar affective reactions to perceived delivery quality because they all experience emotional responses to interpersonal justice (Masterson et al., 2000; Moorman, 1991), or to the possibility that the relationship between themselves and their supervisors is not as strong and positive as it could be (Ferris, Munyon, Basik, \& 
Buckley, 2008). Researchers have established that supervisor delivery is an important component in the formation of employee reactions following a feedback event (Bianci \& Ames, 2008; Brett \& Atwater, 2000; Ferris et al., 2008); the current study suggests that delivery is especially important in the formation of affective reactions across employee age.

One final interesting interaction that resulted from the analyses but was not directly related to age was the two-way interaction between valence and delivery quality. This relationship was either significant or marginally significant in predicting each type of feedback reaction I examined. Each time, the relationship looked roughly the same: better valence and better delivery always resulted in higher affective, cognitive, and motivational reactions for employees of all ages. However, these reactions were especially good in the condition of having positively valenced feedback with high-quality delivery. This again suggests the importance of feedback delivery in developing employees' long-term reactions to a feedback event. Clearly this element of the feedback is important even when other elements, such as valence, are positive. This supports previous researchers in their assertions that supervisors should take note not to gloss over good reviews, as delivery remains important to people even when feedback is good (Bianchi \& Ames, 2008). These results show that these reactions hold up over time, further providing evidence of the importance of feedback delivery quality. This finding has important implications for supervisors. Given that delivery in human resource functions appears to be so important in forming employee reactions of these functions, it may be wise for organizations to 
consider supervisor training programs that emphasize teaching this skill to potential organizational leaders.

Exploratory analyses: Three-way interactions

The three-way interaction between age, perceived content quality, and perceived delivery quality was a marginally significant predictor of employee satisfaction with the appraisal, and a significant predictor of employee perceptions of feedback utility. This relationship revealed that older adults receiving feedback with poor-quality content were more satisfied in this condition with feedback that was high in delivery quality, and they also found this combination to be more useful. Conversely, when older adults received feedback with high-quality content their satisfaction and utility perceptions depended less on delivery quality; in this condition, younger adults were actually more concerned with delivery quality in terms of their affective and cognitive reactions. A different way to examine these relationships can be seen in Figures 19a and $\mathrm{b}$ and 20a and $\mathrm{b}$. These figures show that older adults' affective and cognitive reactions were more dependent on content quality when delivery was poor, while younger adults' affective and cognitive reactions were more dependent on content quality when delivery was good.

Although these findings were not hypothesized, they too can be conceptualized in terms of Socio-emotional Selectivity Theory. According to SST, younger adults are concerned with future opportunities. Because of this, younger adults should place more emphasis on feedback content. Perhaps when feedback content is poor, delivery quality does not matter to younger adults because their reactions are more focused on 
the content. Conversely, older adults are less concerned with content quality according to the tenets of SST, so when content quality is poor their reactions are more focused on delivery. However, when content quality is good, perhaps younger adults are more concerned with delivery because they want to ensure that they are getting credible and specific information regarding their job performance and their supervisor is on board with helping them to improve and become more employable in the future. In this condition older adults are less concerned with delivery quality, perhaps because older adults are less interested in high-quality content whether it is accompanied by good delivery or not.

A similar story is told by Figures $19 \mathrm{a}$ and $\mathrm{b}$ and $20 \mathrm{a}$ and $\mathrm{b}$. In these figures, the relationship is flipped: older adults receiving low-quality delivery are more concerned with feedback content in terms of their satisfaction and perceptions of feedback utility, while younger adults receiving high-quality delivery are more concerned with feedback content. It may be that older adults receiving low-quality delivery perceive this as being indicative of their poor standing with their supervisor, and high-quality content can offset this negativity a bit by giving older employees specific ways in which they can improve and renew a good relationship with their supervisors. Indeed SST posits that older adults are looking to regulate their emotions in a positive way; perhaps some element of the feedback event being high in quality is enough to produce this. By contrast, when older employees receive feedback with high-quality delivery, they perceive no need for high-quality feedback content. Younger adults, however, desire good feedback content, but only when it comes with good delivery 
that indicates the supervisor's credibility and commitment to giving them the correct information and making sure they improve on the job. Future researchers may want to further examine and clarify these links and determine what mechanisms underlie age differences in reacting to content quality depending on variations in other elements of the feedback event. SST suggests that younger adults in general are more focused on feedback content while older adults in general should be more focused on feedback delivery; these findings show that this is the case, but only when certain conditions are present.

Figures $19 \mathrm{a}$ and $19 \mathrm{~b}$

Age by Content by Delivery Interaction: Satisfaction with Appraisal as outcome

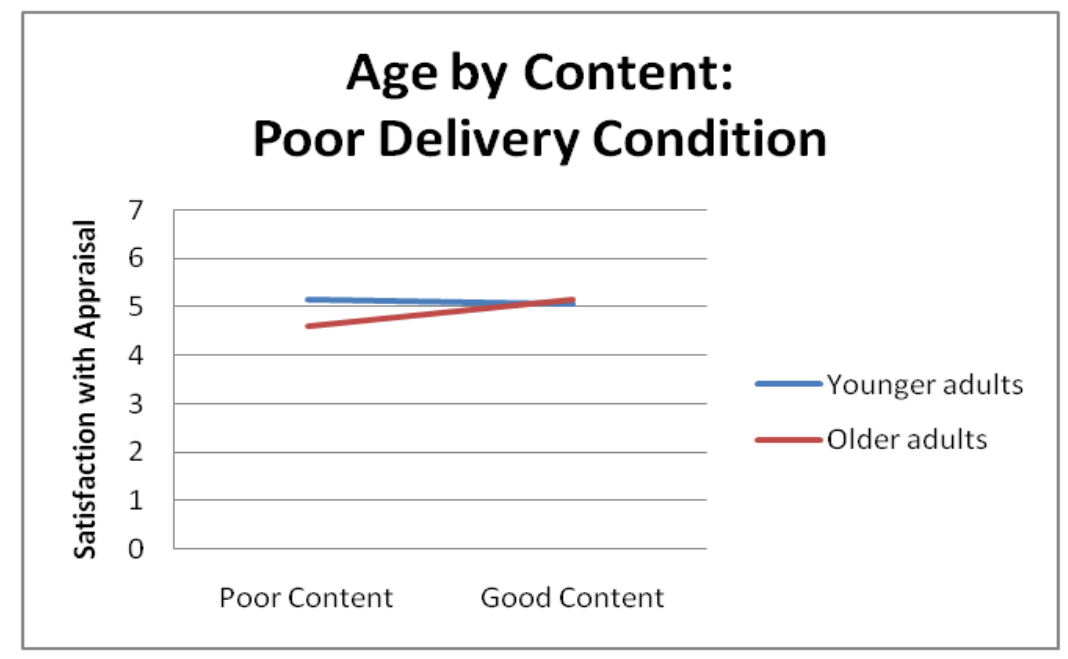




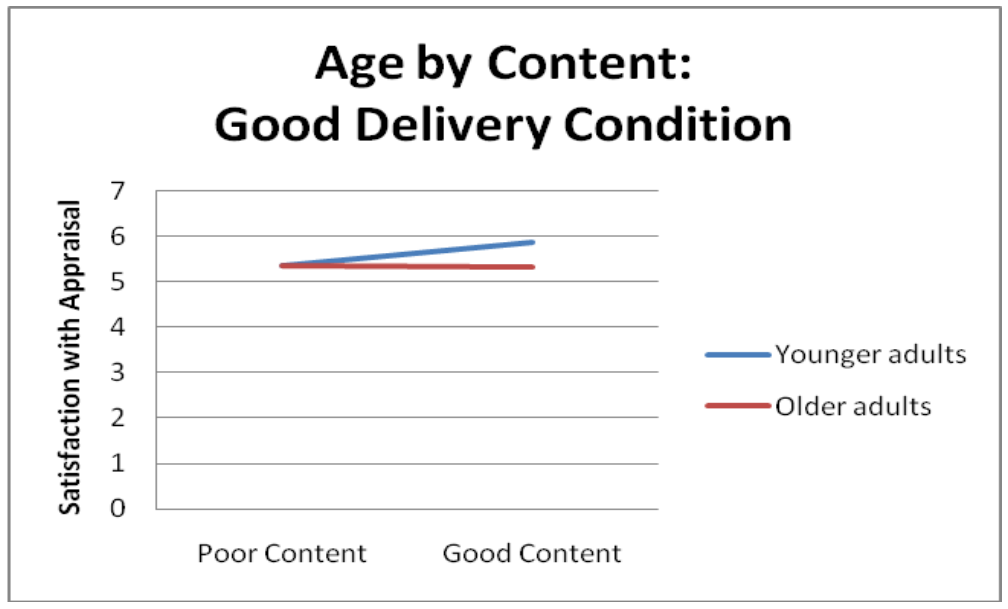

Figures 20a and 20b

Age by Content by Delivery Interaction: Utility of Feedback as outcome

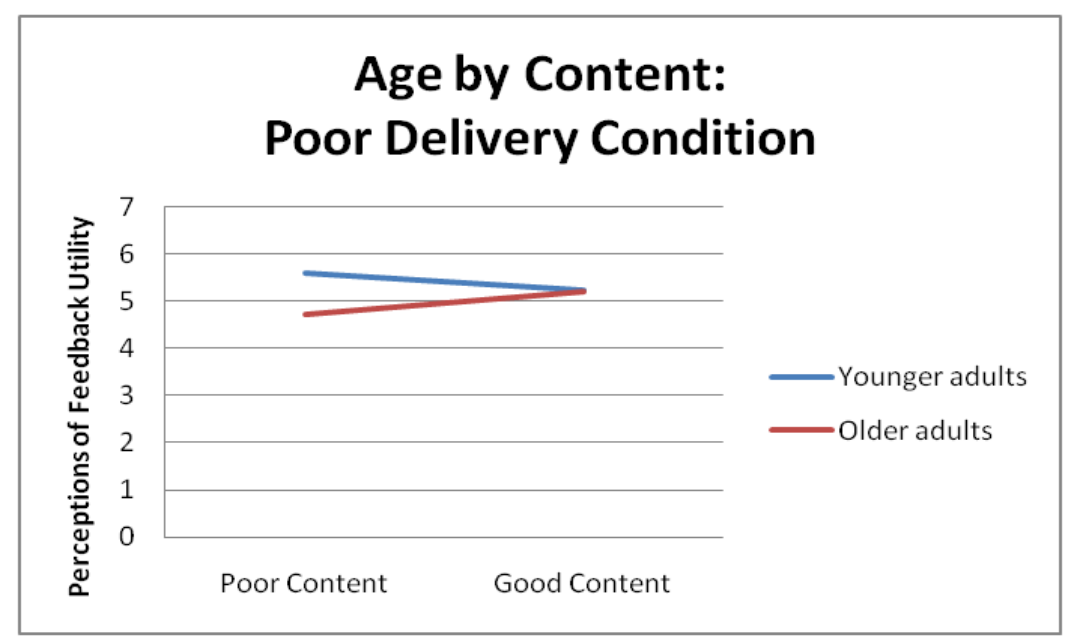




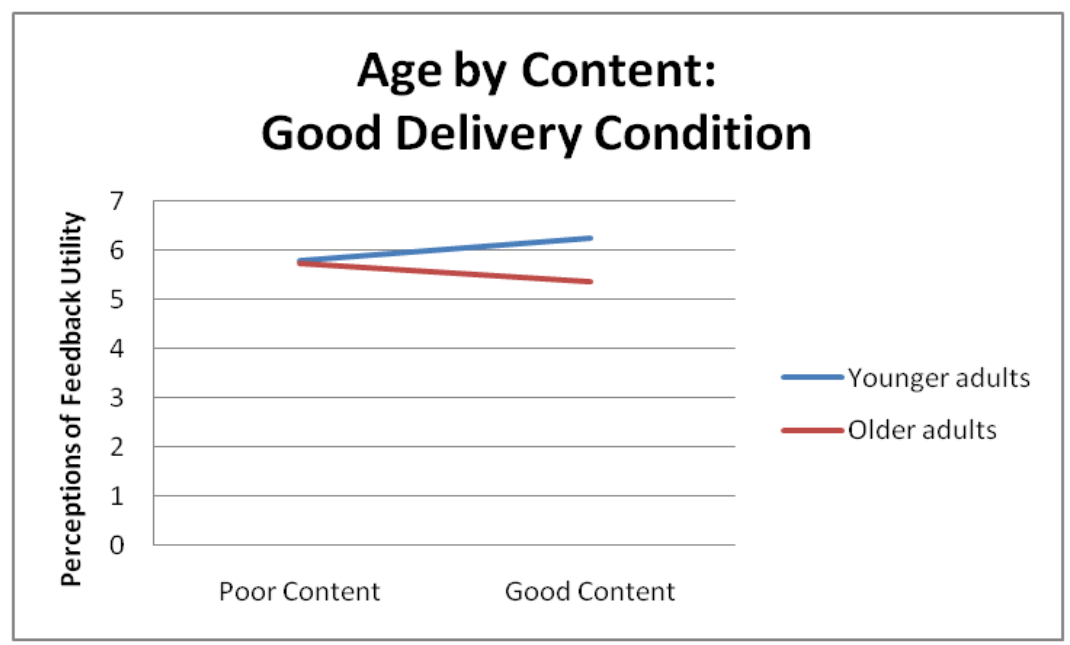

Exploratory analyses: Four-way interactions

The four-way interaction between age, valence, content, and delivery was a significant predictor of employee satisfaction with the appraisal and a marginally significant predictor of employee perceptions of feedback utility. This interaction revealed that older and younger adults had different reactions depending on variations in perceived valence, content, and delivery. One way to conceptualize this relationship is to say that younger adults receiving negative feedback preferred good feedback delivery regardless of content quality, while older adults receiving negative feedback preferred good feedback delivery and good feedback content. Conversely, younger adults receiving positive feedback preferred good feedback content with good feedback delivery, while older adults receiving positive feedback preferred good feedback delivery regardless of content quality. This relationship can be best understood through future research. Because of issues of power and interpretability, four-way interactions in multiple regression are typically avoided and best examined 
through alternative statistical procedures (Aiken \& West, 1993). The inclusion of this higher-order interaction in the current study was mostly to assess its effects on the lower-level interaction terms that were hypothesized. Indeed, the significant threeand four-way interactions found both supported and extended the findings of the twoway interactions: younger adults' reactions are generally more dependent on content quality and older adults' reactions are generally more dependent on delivery quality as proposed by SST, but the higher-order interactions show that this becomes more complex as you incorporate different conditions of the other elements of the feedback event. The nature of this four-way interaction gives us a glimpse of how age interacts with all three elements of a feedback event to produce certain feedback reactions in employees.

One possible explanation of this relationship rests within the tenets of SST. Older adults receiving positive feedback in conjunction with high-quality delivery are most satisfied because these are the elements of feedback that are important to them (and they also perceive this feedback as being the most useful). However, these two elements of feedback are not enough to satisfy younger workers; they need specific and relevant content for even positive feedback to help them in the future. Older adults receiving negative feedback, by contrast, need positive delivery in order to be satisfied, as this positive delivery indicates good social standing within one's work team even in the presence of negative feedback. However, in this condition their satisfaction and utility perceptions also rely on content quality, as this element may also be important in offsetting the negative emotional impact of poor valence and the 
possible decline in the quality of the employee-supervisor relationship that may be perceived in this condition. Younger adults receiving negative feedback preferred high-quality delivery but paid little attention to content quality. Perhaps in this condition delivery quality is most indicative of one's potential for future advancement, since the negative feedback already indicates that one is doing poorly in one's current position and younger adults are already aware in this condition that they need to improve.

Again, these results require further research for better interpretation, and the multifaceted nature of this interaction may be too complex to effectively put into practice. It is tempting to conclude based on the two-way interactions that older adults are more concerned with valence and delivery, while younger adults are more concerned with content. However, it is important to note that the higher-order interacts qualify these relationships in that they seem to be true only given certain conditions. For instance, the three-way interaction between age, valence, and delivery suggests that older adults' affective and cognitive reactions will only be more affected by valence than younger adults when feedback is negative, and more affected by delivery when feedback is positive. The three-way interaction between age, content, and delivery suggests that when content is good, younger adults will actually be more concerned with delivery than older adults. And finally, the four-way interaction between age, valence, content, and delivery indicates that older and younger adults actually switch how much importance they place on content and delivery, depending on whether the feedback is overall positively or negatively valenced. Certainly these 
higher-order findings do indicate that age interacts with the various elements of the feedback event to produce variations in employee affective and cognitive reactions to feedback. Employees of different ages appear to react differently to specific combinations of feedback elements within an event, and future researchers should work to disentangle these more complex combinations if this research is to inform the practice of supervisors in delivering formal performance feedback to employees of all ages.

Limitations and Directions for Future Research

Although the current results reveal promising information regarding age differences in employee feedback reactions, this study is not without limitations. Perhaps the most pressing issue that future research can address is the lack of available validated scales for the measurement of feedback ratings and reactions. For the purposes of this study I used scales similar to those that past researchers in this topic area have used (for instance, Bianchi and Ames' Motivational Reactions Scale). I also used theory to guide the scale development (for instance, the use of organizational justice scales in the place of items assessing feedback content and delivery), as well as my own analyses regarding the theorized three-factor structure of employee feedback reactions. These factor analyses revealed relatively good factor structures for the scales used compared to other possible scales that have been used in the literature, but even for these scales the fit indices (for instance, the RMSEA indices for the affective, cognitive, and motivational reaction scales) were poor. Unfortunately no widely accepted, valid scales that assess these constructs exist to 
date. This may be an artifact of research trends: the study of feedback elements besides valence, such as content and delivery, is a relatively new area of research, as is the multi-dimensional conceptualization of feedback reactions. However, much valuable information can be gained from research that uses similar, high-quality scales across different populations and in different settings. Future researchers should, first and foremost, create and validate scales for this purpose and eliminate the need for other researchers to use scales that are convenient and face valid to assess employee perceptions of feedback elements and their affective, cognitive, and motivational reactions to these elements. This study adds to the literature suggesting this is a fruitful area of research for understanding performance feedback and its effects on employees; valid, widely-used scales can allow this topic area to receive greater research attention and thus result in further interesting and useful findings.

As mentioned above, a quantitative limitation of the study was that the fit indices for the confirmatory factor analyses that were conducted were relatively poor. Besides designing more valid measures, future researchers can further examine this issue through the use of additional confirmatory factor analyses. In the current study it was assumed that perceptions of the three feedback elements (valence, content, and feedback) were all separate and distinct factors, and the analyses were conducted mainly to confirm the three-factor structure of the outcome variables. The information tables provided in Tables 2, 3, and 4 indicates that the correlations among valence, content, and delivery ratings are relatively high. Future researchers may find it beneficial to analyze all the variables included in the analysis to assess the factor 
structure of these variables, and further determine which items are best to include and discard.

One issue inherent in the current study is that data was collected using self-report methods. Participants indicated their perceptions of feedback valence, content, and delivery. I do not have information regarding the actual performance appraisals, so we cannot know how accurate these perceptions were. While I argue that employee perceptions of the feedback is what truly matters in the formation of employee reactions, future research may benefit from the examination of these relationships and how they stack up against the actual performance feedback (objective measures of how positive or negative it was, how much content was provided, and the quality of the delivery).

The time lag design of the study was used in order to assess employee reactions and how they manifest themselves over time, and also to avoid common method bias. It is possible that asking employees to indicate their reactions to the feedback may have impacted their ratings of their perceptions of the feedback elements; I attempted to remedy this by having participants indicate their ratings and their reactions at two different points in time. The measures also specifically indicated that they should be as objective and truthful as possible in their ratings. However, this may have been difficult for the participants, given that this was a retrospective study in which they were asked to remember their most recent performance appraisal events. These instructions were clearly specified, but it is impossible to tell how accurately people remembered and appraised these events. In order to gain more information about 
employee feedback reactions and replicate the current findings, future researchers may want to go at the problem a different way. It would certainly be interesting to conduct a lab study in which valence, content, and delivery quality are manipulated and employee reactions are then recorded, measured, and analyzed based on their age. This would not only provide researchers with a better understanding of how feedback elements lead to employee reactions (and, pertinent to this study, how age interacts with these elements to form more positive or negative reactions) but also supplement real-world evidence of employee feedback reactions with lab evidence supporting the notion that variations in feedback elements such as valence, content, and delivery are predictive in forming these reactions.

The sample used in this study consisted of relatively few older adults as compared to younger adults, with only $1.9 \%$ of the sample being in their fifties, and none of the sample being in their sixties. This was partly due to retirement trends in China (Davies, Lueng, Luk, \& Wong, 1995). Typically the Chinese laws dictate that professional women should retire at age 55, while professional men should retire at age 60. This trend occurs even earlier with blue-collar workers: Chinese men typically retire around the age of 55, while women in these industries typically retire around 50 (Li et al., 2000). In the United States, the Age Discrimination in Employment Act (ADEA; Department of Labor, 2010) denotes that an "older worker" is one who is over the age of 40 , and certain rights and policies apply to this class of people. Chinese law discourages employers from discriminating against potential workers on the basis of gender, culture, or religious beliefs (Li et al., 2000), 
but with the exception of practical guidelines provided to organizations in Hong Kong for how to manage older employees Chinese law provides no cut-offs or policies regarding business practice with aging workers. If anything, the early age at which Chinese employees retire indicates that an "older worker" is actually someone younger than the age of 40 . This limitation may not have allowed us to fully see how older age manifests itself in terms of feedback reactions.

Moreover, the sample used was mostly male, Chinese, and working within one large organization in China. The latter is a limitation that needs to be remedied by further replications of this research; the former fits one of the purposes of the current study — adding cross-national and cross-cultural constructs and data to the performance appraisal literature — but also creates some potential limitations to the study's results. As previously mentioned, Chinese employees have a lot in common with American employees, but they also differ in many ways. Hofstede's five cultural dimensions (Hofstede \& Bond, 1984) provide one framework for understanding these differences, but some research has suggested that these dimensions do not generalize well across cultures (Namov \& Puffer, 2000). Thus, one might question what kinds of practical applications the current study might have for workers in the United States. Differences in societal norms among the two nations could have contributed to some of the effects seen in this study. For one thing, in China there is a strong emphasis on treating older individuals with increased respect (Tsui \& O’Reilly, 1989). Thus, delivery may have been especially important to the older individuals in this sample, because high-quality delivery can be synonymous with respectful delivery and older 
adults come to expect this kind of treatment. Business practices in China are also markedly different from those in the United States. For instance, recent research conducted in China has revealed the importance of Guanxi, or the existence of a formal, reciprocal network relationship between members of an organization (pertinent to this case, especially that between employees and their immediate supervisors). It has been suggested that supervisor-subordinate Guanxi is extremely important in forming supervisor trust (Farh, Tsui, Xin, \& Cheng, 1998) and in predicting the performance of extra-role behaviors (Hui et al., 2004). Additionally, researchers have suggested that the Guanxi relationship is actually distinct from LMX (Law, Wong, Wang, \& Wang, 2000). This construct was not assessed in the current study; I argue that supervisor-subordinate dyads all carry with them this relationship by their very nature, and a construct with so little variance will have little predictive power in terms of how performance appraisal reactions are formed. However, future researchers may want to examine variations in how the Guanxi relationship is perceived by employees in China and how this affects their reactions to various supervisor-led human resources initiatives.

Despite the differences between Chinese and American business culture, I argue that China is similar to the United States in that it is a nation experiencing an aging workforce and increasing age diversity. Further suggesting similarity between the two nations, recent organizational research conducted in China has shown that employees are becoming less traditional in their work and their interactions with their supervisors (Aryee \& Chen, 2006; Hui, Lee, \& Rousseau, 2004). Moreover, 
increasing globalization and outsourcing indicate that we need to better understand workers from all different cultures and nations if we are to work with them effectively (and, in this case, manage and deliver feedback effectively). The findings of the current study provide interesting evidence that age differences may be at play in forming employee reactions to feedback, and future researchers may benefit from examining how these results generalize to other populations. Perhaps most obviously, it would be interesting to see how these relationships look in an American organization, as our conceptualizations of aging and age at work are different than those in China and are changing rapidly as the workforce ages and expands in terms of age diversity. However, researchers may also examine how these relationships appear in smaller organizations, as well as organizations that are more genderdiverse. Such information would be useful in further determining how age and other individual differences manifest themselves in work settings of all kinds. The current study did not truly assess cross-cultural comparisons, as only one culture was examined. However, future researchers may find it useful to compare other nations with differing characteristics in terms of how performance is appraised and how employees react to this appraisal, as these more proximal relationships are likely to be impacted by more distal variables such as culture and nationality. In this increasingly globalized world of work, these differences, or lack thereof, are especially important to understand.

Informational and interpersonal justice regarding the feedback events in question were measured and renamed into assessments of feedback "content" and "delivery". 
As I mentioned in the introduction, I believe there is a sound theoretical reason to do so. However, perceptions of distributive and procedural justice were not assessed. As was described earlier, distributive justice refers to perceptions of fair outcomes, while procedural justice refers to perceptions of fairness within a process. Certainly these are two dimensions that pertain to performance appraisal events; employees will likely have higher reactions when they perceive a performance appraisal as fair throughout its administration and in terms of the outcome (in this case, the valence of the feedback). Research has indeed shown that employees have marked reactions based on these two constructs within performance appraisal settings (Erdogan, 2002). In the current study it was expected that perceptions of distributive and procedural justice were randomly dispersed among participants of all ages. However, there are reasonably high correlations among the dimensions of justice (Colquitt et al., 2001), and thus perceptions of these unmeasured justice constructs could have affected other perceptions and reactions. While the current study collected data regarding perceptions of fairness within the context of supervisor-employee treatment, no data was collected regarding the degree to which respondents perceived the feedback they were ultimately given as being fair. Future researchers should examine the effects of controlling these two justice dimensions in order to assess how their inclusion affects content and delivery ratings. On another note, justice may be a perception of a formal feedback event, but it can also be an outcome. Applicant reactions literature, for instance, places employee perceptions of justice regarding a selection test as a reaction to the selection procedure (Hausknecht, Day, \& Thomas, 2004; Ployhart, \& 
Ryan, 1997; Smither, Reilly, Millsap, Pearlman, \& Stoffey, 1993). The model of the current study did not include justice perceptions as an outcome, but in the future it may be wise to explore the possibility that justice perceptions are integrated into employee feedback reactions in a more complex way than was assessed here.

This study sought to predict employee reactions to a feedback event from their perceptions of the valence, content, and delivery quality of that feedback event. Ultimately, it was theorized that these feedback reactions will in some way lead to performance, which is what supervisors ideally want to affect with their performance appraisals. The current study did not directly measure behavioral reactions (for instance, job performance) following the feedback events in question. Instead, the logical leap was made that employee affect, cognition, and motivation following the feedback will likely manifest through the employee's behavior on the job. Other studies assessing employee feedback reactions have made a similar leap (Bianchi \& Ames, 2008; Brett \& Atwater, 2001). However, it is possible that while all of these reactions are occurring within individuals, their performance on the job actually has little to do with them. There is research evidence, for instance, suggesting that peoples' attitudes and behaviors are not as correlated as one might think (Azjen, 1991; Smith \& Swinyard, 1983; Sutton, 1998). I argue that when considering the workplace context, affective, cognitive, and motivational reactions are still vitally important to understand. Even if an employee's job behavior immediately following a performance appraisal event does not show it, the fact that he or she is heavily dissatisfied with the feedback event is likely to manifest itself through his or her job 
satisfaction or organizational commitment. However, in order to truly understand the direct link between performance feedback and employee performance following the feedback, future researchers need to gain access to employee job performance ratings and assess behavioral reactions as well as those that are psychological. This research, in conjunction with past feedback reactions literature, provides an interesting supposition of how that link should take place, but a closer look at employee behavior as a result of how they perceive and react to performance feedback is needed. Following this logic, it also makes sense that feedback reactions will impact other things besides job performance following a feedback event. For instance, research has suggested that feedback reactions may be linked to organizational commitment (Bianchi \& Ames, 2008; Brett \& Atwater, 2001), LMX (Bianchi \& Ames, 2008), and development intentions (Brett \& Atwater, 2001). It is possible that other outcomes are important as well; it may be that feedback reactions over time predict turnover, or career development intentions. Organizational justice research has shown that the events that happen at work impact important individual and organizational outcomes (Colquitt, 2001; Colquitt et al., 2001; Moorman, 1991); future researchers can examine these outcomes within the context of performance appraisal reactions.

One issue the current study did not address is that of technology in the workplace. Certainly the changing nature of work can be partly attributed to advances in technology: these advances have made it easier to globalize and virtualize organizational practices (Liebold \& Voelpel, 2006). Given that performance appraisal is such a wide-spread and common practice, it is not a stretch to consider the fact that 
technology may soon play a role in this domain as well. The current study, in conjecture with previous research (Bianchi \& Ames, 2008; Brett \& Atwater, 2001), has shown the importance of feedback delivery in forming employee perceptions and reactions; it will be a challenge for organizations to keep the more important elements of a feedback event present as technology enters this context. Research suggests that with adequate instruction in the right conditions, older adults can be just as likely as younger adults to adopt the use of technology in the workplace (Morris \& Venkatesh, 2000; Selwyn, 2004). However, future researchers may want to examine age differences in feedback perceptions and reactions in conditions in which the feedback is delivered or administered using some form of technology. As the workplace, and subsequently human resources practice, becomes more technologically savvy, growing increasingly aware of the attitudes and reactions of employees of all ages is essential as we attempt to continue to effectively manage and supervise all employees.

\section{Theoretical Development}

Certain tenets of Socio-emotional Selectivity Theory (Carstensen, 1991; 1992) appear to be present in our sample: younger adults, showing more inclination toward growth and development, tended to prefer feedback that was rich in relevant content, while older adults, being more emotionally-focused, tended to have reactions that heavily depended on feedback valence and delivery quality. However, some unexpected findings occurred as well. Specifically, age appeared to be negatively correlated with all three types of reactions after the time lag (or, to put it another way, 
over time older employees typically reported being less satisfied and motivated by the feedback event, and also reported finding it less useful). SST suggests that older adults tend focus on emotional regulation, and thus tend to regulate their emotions to be positive over time (Carstensen \& Mikels, 2005). Indeed, older adults have been found to attend to negative information more immediately, but have better memory for positive information over time (Turk-Charles, Mather, \& Carstensen, 2003; Mather \& Carstensen, 2003). Thus, one would expect that their reactions over time would be higher than those of younger adults. We found just the opposite: older adults consistently reported lower reactions overall, as can be seen in many of the attached figures.

As was previously mentioned, the age range of the sample in the current study may not have allowed for the true reactions of "older adults" to be observed, which certainly affects the age-related findings presented here. Kanfer and Ackerman, for instance, suggested that as adults age they undergo trajectories of loss (of cognitive ability, for instance), growth (of crystallized intellectual ability), reorganization (of goals, for instance), and exchange (2004). Where one is in his or her lifespan will affect where he or she is on these trajectories; the relatively middle-aged sample in the current study made it impossible to assess the extent to which these age-related patterns and suggested behaviors and characteristics influenced their perceptions of and reactions to performance feedback. However, one possible issue is that SST does not just operate within the context of chronological age, but also within the context of the stage one is in. For instance, a longitudinal study of college students found that 
while college freshmen, new to a university, displayed many of the SST-related characteristics of younger adults, college seniors, who were soon to graduate, tended to behave more like older adults are proposed to behave in this theory (Fredrickson, 1995). Thus, SST may not necessarily be measured in terms of age, but can also be looked at from a career stage perspective. One would expect that people closer to the beginnings of their careers would be more concerned with growth and opportunity, while people closer to the end of their careers would be more concerned with close work relationships and positive interpersonal treatment. To be sure, there is some correlation between age and career stage; generally younger adults are closer to the beginning of their careers while older adults are closer to exiting the workforce. However, in this changing world of work, people of all ages now occupy all stages of the career spectrum. Future researchers might benefit from examining these relationships from a career stage perspective rather than a strictly chronological age perspective. Additionally, it may be interesting to see how these performance appraisal reactions operate as a function of perceived age and age norms (Avery et al., 2007; Zepelin, 1987) and perceived career stage (Kirchmeyer, 1995; Swanson \& D'Achiardi, 2005). These are not only functions of actual age and career stage, but also of self-other comparisons, culture, and societal norms (Barak \& Schiffman, 1981; Barak, 1987). Because retirement trends in China are so different from those in the United States, it is reasonable to conclude that perceived age and career stage may operate very differently in these two nations. It may be that these perceptions outweigh the predictive power of objective chronological age in determining 
perceptions of and reactions to performance feedback. Future researchers may want to utilize measures of cognitive age to better assess what these relationships are (Barak, 1987). To my knowledge, no measure assessing perceived career stage currently exists; such a measure may be beneficial to our understanding of if and how SST operates within the workplace.

One other possibility that was previously mentioned is that we are seeing the effects of generational desires and work needs rather than evidence of an aging theory. A generation is identified as "a group or cohort that shares birth years, age location, and significant life events at critical developmental stages" (Kupperschmidt, 2000). Researchers have typically divided the workforce into four main generations: traditional (those born before 1940), Baby Boomers (those born between 1940 and 1960), Generation Xers (those born between 1960 and 1980), and Millennials (those born after 1980, the youngest members of the workforce). Each of these generations is expected to have different interests and desires, both in life and in the work domain.

Millennials, for instance, tend to view work as being just a job, and not central to their sense of self. They look at work as an opportunity to enhance their marketability, and they demand managers who are competent and helpful (Kupperschmidt, 2000). It may be that younger adults view high-quality feedback content as a sign of supervisor competence, and thus they have higher affective, cognitive, and motivational reactions to such feedback. Additionally, millennials have been said to "know the importance of constantly gaining and applying new 
knowledge and skills" (Payne \& Makiney, 2008), and are described in the literature as being ambitious, demanding, and desiring of feedback (Deal, 2006). These descriptions may help to explain why younger adults tend to place greater emphasis on feedback content than older adults, and also partially explains why younger adults may be more desiring of feedback delivery when feedback is negatively valenced. Jennifer Deal describes millennials as having "tender little egos" that need to be noticed and told they are doing well at work (2006); good delivery in the absence of positive feedback could provide this for younger adults. This ego theory may also help to explain why younger adults prefer both good delivery and good content with positive feedback, as these elements all indicate the good job they are doing and their high standing within the organization in terms of job performance. Overall, younger adults reported higher satisfaction, motivation, and perceptions of usefulness of the feedback than older adults over time. This is consistent with literature suggesting that younger generations are those that place the greatest emphasis on detailed feedback at work (Deal, 2006; Kupperschmidt, 2000).

Older generations, by contrast, are portrayed in the literature as viewing work to be a more central part of themselves (Kupperschmidt, 2000). They do not always view authority as credible, but tend to respect them nonetheless. This may help to explain the more marked reactions to feedback valence and delivery seen by older adults: if they view work as being a central part of themselves, it truly matters to them whether they are doing a good or poor job, and it truly matters to them how organizational entities such as supervisors treat them. Indeed, recent research has 
shown that older generations tend to value the building of social relationships more than their younger counterparts, which again may help to explain the importance that older adults tend to place on feedback delivery (Twenge, Campbell, Hoffman, \& Lance, 2010). This may also help to explain why older adults don't place as great of an emphasis on feedback content; if they do not typically view authority as being credible, the information that an authority figure gives them is much less important to their satisfaction, motivation, and perceptions of usefulness. providing further explanation for why they may not value feedback as much as younger adults do.

Generational effects can not necessarily be inferred from the current study. For one thing, generations in China, are, by definition, different from those in the United States because they have had completely different life events at critical developmental stages. It may be that generations in China operate completely differently from those in Western nations. However, the notion of cohort effects in the workplace is certainly an interesting one, and is budding as a relatively new area of research (Cennamo \& Gardner, 2008; Twenge \& Campbell, 2008; Twenge et al., 2010; Wong et al., 2008). Future researchers may follow employees over several points in time to assess whether differences in feedback reactions are due solely to age or career stage, or if generational attitudes and values are playing a role in how they respond to feedback valence, content, and delivery (and subsequently how they behave on the job following a feedback event). In the more distant future, new generations will enter the workforce among the previously established workforce 
generations. It will be interesting to see how their own values and skills will affect their perceptions of human resource functions and their reactions to these functions. 


\section{Conclusion}

The current findings provide further evidence that the consideration of individual differences (in this case, chronological age) is vitally important in the workplace. The findings suggest that, holding constant elements of familiarity and similarity with one's supervisor, an employee's reactions to his or her perceptions of feedback valence, content, and delivery will differ based on his or her age. Specifically, older adults' affective, cognitive, and motivational reactions to feedback depend more heavily on perceived feedback valence than the reactions of younger adults. Older adults' perceptions of utility tend to depend more heavily on their ratings of perceived feedback delivery, while younger adults' perceptions of utility tend to depend more heavily on their ratings of content. Older adults' motivational reactions to feedback tend to depend, again, on ratings of delivery, while younger adults' motivational reactions depend more on ratings of content. Younger adults' satisfaction and perceptions of usefulness tend to depend more heavily on perceived delivery quality when feedback is regarded as being negative, and older adults' satisfaction and perceptions of usefulness tend to depend more heavily on perceived delivery quality when feedback is regarded as being positive. Older adults tend to be more concerned with perceived delivery quality when feedback content is poor, while younger adults tend to be more concerned with perceived delivery quality when feedback content quality is good. And finally, employees of different ages appear to have different affective and cognitive reactions to various combinations of perceived feedback valence, content quality, and delivery quality. Taken together, these results indicate 
that age differences research does have its place in human resources research, and these variations in perceptions and reactions need to be considered both by researchers and practitioners as we seek to build aging theory and deliver feedback that is efficient and effective for all employees.

One contribution of the current study is that it reaffirms researchers' relatively new trend of examining feedback as a multi-faceted phenomenon. Bianchi and Ames (2008) were among the first to look at feedback valence, content, and delivery simultaneously. The current study shows that these are distinct constructs within a feedback event and are differentially appealing to different people receiving the feedback. One way that the current study builds on previous feedback reactions studies is that it utilizes a time lagged component. Most feedback reactions studies have assessed ratings of feedback elements and employee reactions to these elements at roughly the same time (Bianchi \& Ames, 2008; Brett \& Atwater, 2001). The current study reveals that even over time, reactions to a feedback event persist. As an artifact of this research design, the current study reveals that time-lagged reactions actually differ slightly from immediate reactions. Specifically, content perceptions no longer significantly predict affective, cognitive, and motivational reactions to a feedback event over time, but delivery perceptions do. This again points to the importance of considering the multi-dimensional nature of feedback in this research area, and especially points to the importance of supervisor delivery in administering feedback that fosters positive employee reactions. One relationship that consistently turned up as a predictor of employee satisfaction, utility perceptions, and post- 
feedback motivation was the interaction of perceived feedback valence and perceived delivery quality. Specifically, positive valence was even more satisfying, useful, and motivating when delivery quality was good as well. Supervisors would be wise to consider the relatively large impact their delivery has during a feedback event, even in instances when the feedback is positive.

Overall, the current findings provide supervisors with a wealth of information as they attempt to find ways to better manage their employees. Supervisors can use this information as a jumping off point as they seek to garner the reactions they view as being most important from their subordinates of all ages. As previously mentioned, supervisors can do little to control the valence of the feedback they are delivering; this is ideally dependent on the performance of their employees (although research has shown that biases such as halo and negativity bias can influence how supervisors rate their subordinates independently of actual employee performance. For more information, see Feldman, 1981). However, these findings confirm previous research suggesting that there are other elements of the feedback that supervisors can focus on to improve employee morale regarding the feedback event. This research extends previous research by showing that this morale can vary depending on characteristics of the employee and what elements of the feedback event they find important. Socioemotional Selectivity Theory provides one theoretical underpinning for explaining why these variations might occur.

Perhaps above all, the current findings leave us hopeful. The suggestion that employee differences need to be taken into account more thoroughly in human 
resources activities is supported here with the revelation of age differences in employee reactions to formal performance feedback. Using this suggestion as a guideline, we can move toward developing theories and practices to better accommodate all types of employees and ultimately develop a more satisfied and efficient workforce in the face of the dramatically changing nature of work. The current study reveals slightly discouraging information regarding the use of formal performance appraisals with older employees, as they exhibited overall more negative reactions to performance feedback than did younger adults. However, these results call to attention the need for future researchers and organizational practitioners to expend more time and money on other practices that may satisfy and motivate older workers. Recent research has shown that HR policies that garner commitment from employees are more effective with older adults (Kooji, Jansen, Dikkers, \& de Lange, 2010); further research should be conducted to determine how human resource practices in organizations can engage and satisfy all workers (Barnes-Farrell \& Matthews, 2007). Researchers have described the changing workforce as an obstacle to organizational researchers and practitioners; I argue that it is an opportunity to change the way we understand, satisfy and retain all of our valuable employees. 
References

Aiken, L. S. \& West, S. G. (1991). Multiple regression: Testing and interpreting interactions. Thousand Oaks, CA: Sage.

Alas, R. (2009). Implementation of changes in Chinese organizations: Groping a way through the darkness. Oxford, UK: Chandos Publishing.

Albright, M. D. \& Levy, P. E. (1995). The effects of source credibility and performance rating discrepancy on reactions to multiple raters. Journal of Applied Social Psychology, 25, 577-600.

Arnold, H. J. (1981). A test of the validity of the multiplicative hypothesis of expectancy-valence theories of work motivation. Academy of Management, 24, $128-141$.

Aryee, S. \& Chen, Z. X. (2006). Leader-member exchange in a Chinese context: Antecedents, the mediating role of psychological empowerment and outcomes. Journal of Business Research, 59, 793-801.

Atchley, R. C. (1989). A continuity theory of normal aging. The Gerontologist, 29, 183-190.

Avery, D. R., McKay, P. F., \& Wilson, D. C. (2007). Engaging the aging workforce: The relationship between perceived age similarity, satisfaction with coworkers, and employee engagement. Journal of Applied Psychology, 92, 1542-1556.

Avolio, B. J., Waldman, D. A., McDaniel, M. A. (1990). Age and work performance in nonmanagerial jobs: The effects of experience and occupation type. Academy of Management Journal, 33, 407-422. 
Azjen, I. (1991). The theory of planned behavior. Organizational Behavior and Human Decision Processes, 50, 179-211.

Ajzen, I. \& Fishbein, M. (2000). Attitudes and the attitude-behavior relation: Reasoned and automatic processes. European Review of Social Psychology, 11.

Baltes, P. B. \& Baltes, M. M. (1990). Psychological perspectives on successful aging: The model of selective optimization with compensation. In P. B. Baltes \& M. M. Baltes (Eds.), Successful Aging: Perspectives from the Behavioral Sciences. New York, NY: Cambridge University Press.

Barak, B. (1987). Cognitive age: A new multidimensional approach to measuring age identity. International Journal of Aging and Human Development, 25, 109-128.

Barak, B. \& Schiffman, L. G. (1981). Cognitive age: A nonchronological age variable. Advances in Consumer Research, 8, 602-606.

Barnes-Farrell, J. \& Matthews, R. (2007). Age and work attitudes. In K. Schultz \& G. Adams (Eds.), Aging and Work in the $21^{\text {st }}$ Century. Mahwah, NJ: Lawrence Earlbaum.

Baron, R.A. (1993). Criticism (informal negative feedback) as a source of perceived unfairness in organizations: Effects, mechanisms, and countermeasures. In R. Cropanzano (Ed.), Justice in the Workplace: Approaching fairness in human resource management: 155-170. Hillsdale, NJ: Erlbaum.

Barrick, M. R., Stewart, G. L., \& Pitrowski, M. (2002). Personality and job performance: Test of the mediating effects of motivation among sales representatives. Journal of Applied Psychology, 87, 1-9. 
Bauer, T. N. \& Green, S. G. (1996). Development of leader-member exchange: A longitudinal test. Academy of Management, 39, 1538-1567.

Bianchi, E. \& Ames, D. R. (2008, August). What you say and how you say it: The impact offeedback valence, content, and delivery. Paper presented at the 2008 Academy of Management Annual Meeting, Anaheim, CA.

Borman, W. C. (1997). 360 degree ratings: An analysis of assumptions and a research agenda for evaluating their validity. Human Resource Management Review, 7, 299-315.

Brett, J.F. \& Atwater, L.E. (2001). 360 degree feedback: Accuracy, reactions, and perceptions of usefulness. Journal of Applied Psychology, 86, 930-942.

Capsi, A., Roberts, B. W., \& Shiner, R. L. (2005). Personality development: Stability and change. Annual Review of Psychology, 56, 453-484.

Carstensen, L. L. (1991). Selectivity theory: Social activity in life-span context. In K. W. Schaie (Ed.), Annual review of gerontology and geriatrics (Vol. 11, pp. 195217).

Carstensen, L. L. (1992). Social and emotional patterns in adulthood: Support for Socio-emotional selectivity theory. Psychology and Aging, 7, 331-338.

Carstensen, L. L. \& Turk-Charles, S. (1994). The salience of emotion across the adult life-span. Psychology and Aging, 9, 259-264.

Carstensen, L. L., Isaacowitz, D., \& Turk-Charles, S. T. (1999). Taking time seriously: A theory of Socio-emotional selectivity. American Psychologist, 54, 165-181. 
Carstensen, L. L. \& Mikels, J. A. (2005). At the intersection of emotion and cognition. Current Directions in Psychological Science, 14, 117-121.

Cascio, W. F. \& Aguinis, H. (2005). Applied Psychology in Human Resource Management ( $6^{\text {th }}$ Ed.). Upper Saddle River, NJ: Prentice Hall.

Cennamo, L. \& Gardner, D. (2008). Generational differences in work values, outcomes and person-organization values fit. Journal of Managerial Psychology, 23, 891-906.

Chen, Z. X. \& Francesco, A. M. (2000). Employee demography, organizational commitment, and turnover intentions in China: Do cultural differences matter? Human Relations, 53, 869-887.

Colquitt, J. A. (2001). On the dimensionality of organizational justice: A construct validation of a measure. Journal of Applied Psychology, 86, 386-400.

Colquitt, J. A., Conlon, D. E., Wesson, M. J., Porter, C. O. L. H., \& Ng, K. Y. (2001). Justice at the millennium: A meta-analytic review of 25 years of organizational justice research. Journal of Applied Psychology, 86, 425-445.

Cronbach, L. J. (1951). Coefficient alpha and the internal structure of tests. Psychometrics, 16, 297-334.

D’Amato, A. \& Herzfeldt, R. (2008). Learning orientation, organizational commitment and talent retention across generations. Journal of Managerial Psychology, 23, 929-953.

Deal, J. (2006). Retiring the generation gap: How employees young and old can find common ground. San Francisco, CA: Jossey-Bass. 
Department of Labor (2010). Age Discrimination in Employment Act of 1967. Retrieved from http://www.doleta.gov/Seniors/html docs/docs/adea.cfm.

Dobbins, G. H., Cardy, R. L., \& Platz-Vieno, S. J. (1990). A contingency approach to appraisal satisfaction: An initial investigation of the joint effects of organizational variables and appraisal characteristics. Journal of Management, 16, 619-632.

Ebner, N. C., Freund, A. M., \& Baltes, P. B. (2006). Developmental changes in personal goal orientation from young to late adulthood: From striving for gains to maintenance and prevention of losses. Psychology and Aging, 21, 664-678.

Erdogan, B. (2002). Antecedents and consequences of justice perceptions in performance appraisals. Human Resource Management Review, 12, 555-578.

Farh, J., Tsui, A. S., Xin, K., \& Cheng, B. (1998). The influence of relational demography and Guanxi: The Chinese case. Organization Science, 9, 471-488.

Fazio, R. H. (1990). Multiple processes by which attitudes guide behavior: The mode model as an integrative framework. In Advances in Experimental Social Psychology (Vol. 23), San Diego, CA: Academic Press.

Feldman, J. M. (1981). Beyond attribution theory: Cognitive processes in performance appraisal. Journal of Applied Psychology, 66, 127-148.

Ferris, G. R., Munyon, T. P., Basik, K., \& Buckley, M. R. (2008). The performance evaluation context: Social, emotional, cognitive, political, and relationship components. Human Resource Management Review, 18, 146-163.

Festinger, L. (1954). A theory of social comparison processes. Human Relations, 7, 117-140. 
Field, D. (1999). Continuity and change in friendships in advanced old age: Findings from the Berkeley older generation study. International Journal of Aging \& Human Development, 48, 325-346.

Field, D. \& Millsap, R. E. (1991). Personality in old age: Continuity or change? The Journal of Gerontology, 46, 299-308.

Fingerman, K. L., Hay, E. L., \& Birditt, K. S. (2004). The best of ties, the worst of ties: Close, problematic, and ambivalent social relationships. Journal of Marriage and Family, 66, 792-808.

Folger, R. \& Cropanzano, R. S. (1998). Organizational justice and human resource management. Beverly Hills, CA: Sage Publishers.

Ford, J. K. \& Noe, R. A. (1987). Self-assessed training needs: The effects of attitudes toward training, managerial level, and function. Personnel Psychology, 40, 39-53.

Fredrickson, B. L. (1995). Socio-emotional behavior at the end of college life. Journal of Social and Personal Relationships, 12, 261-276.

Freund, A. M. (2006). Age-differential motivational consequences of optimization versus compensation focus in younger and older adults. Psychology and Aging, $21,240-252$.

Freund, A. M. \& Baltes, P. B. (2000). Life-management strategies of selection, optimization and compensation: Measurement by self-report and construct validity. Journal of Personality and Social Psychology, 82, 642-662.

Fung, H. H., Carstensen, L. L., \& Lang, F. R. (2001). Age-related patterns in social networks among European Americans and African Americans: Implications for 
Socio-emotional selectivity across the life span. The International Journal of Aging and Human Development, 52, 185-206.

Fung, H. H., Carstensen, L. L., \& Lutz, A. M. (1999). Influence of time on social preferences: Implications for lifespan development. Psychology and Aging, 14, 595-604.

Fung, H. H., Lai, P., \& Ng, R. (2001). Age differences in social preferences among Taiwanese and mainland Chinese: The role of perceived time. Psychology and Aging, 16, 351-356.

Gelfand, M. J., Bwahuk, D. P. S., Nishii, L. H., \& Bechtold, D. J. (2004).

Individualism and collectivism. In R. J. House, P. J. Hanges, M. Javidan, . W. Dorfman, \& V. Gupta (Eds.), Culture, leadership, and organizations: The GLOBE study of 62 societies. Thousand Oaks, CA: Sage Publishing.

Gold, D. P., Andres, D., Etezadi, J., Arbuckle, T., Schwartzman, A., \& Chaikelson, J. (1995). Structural equation model of intellectual change and continuity and predictors of intelligence in older men. Psychology and Aging, 105, 294-303.

Graen, G. B. \& Uhl-Bien, M. (1995). Relationship-based approach to leadership: Development of a leader-member exchange (LMX) theory of leadership over 25 years: Applying a multi-level multi-domain perspective. The Leadership Quarterly, 6, 219-247.

Greenberg, J. (1986). Determinants of perceived fairness of performance evaluations. Journal of Applied Psychology, 71, 340-342. 
Greenberg, J. (1990). Organizational justice: Yesterday, today, and tomorrow. Journal of Management, 16, 399-432.

Greenberg, J. (1993). Studying organizational justice cross-culturally: Fundamental challenges. International Journal of Conflict Management, 12, 365-375.

Hashtroudi, S., Johnson, M. K., \& Chrosniak, L. D. (1990). Aging and qualitative characteristics of memories for perceived and imagined complex events. Psychology and Aging, 5, 119-126.

Hobson, C. J. \& Gibson, F. W. (1983). Policy capturing as an approach to understanding and improving performance appraisal: A review of the literature. Academy of Management Review, 8, 640-649.

Hofstede, G. (1980). Culture and organizations. International Studies of Management \& Organization, 10, 15-41.

Hofstede, G. \& Bond, M. H. (1984). Hofstede's culture dimensions: An independent validation using Rokeach's value survey. Journal of Cross-Cultural Psychology, 15, 417-433.

Holzbach, R. L. (1978). Rater bias in performance ratings: Superior, self-, and peer ratings. Journal of Applied Psychology, 63, 579-588.

House, R. J., Hanges, P. J., Javidan, M., Dorfman, W., \& Gupta, V. (2004). Culture, leadership, and organizations: The GLOBE study of 62 societies. Thousand Oaks, CA: Sage Publishing.

House, J. S., Lantz, P. M., \& Herd, P. (2005). Continuity and change in the social stratification of aging and health over the life course: Evidence from a nationally 
representative longitudinal study from 1986 to 2001/2002 (Americans' Changing Lives Study). Journals of Gerontology: SERIES B, 60B, 15-26.

Hui, C., Lee, C., \& Rousseau, D. M. (2004). Employment relationships in China: Do workers relate to the organization or to people? Organization Science, 15, 232240.

Ilgen, D.R., Fisher, D.D., \& Taylor, M.S. (1979). Consequences of individual feedback on behavior in organizations. Journal of Applied Psychology, 64, 349371.

Inderrieden, E. J., Keaveny, T. J., \& Allen, R. E. (1988). Predictors of employee satisfaction with the performance appraisal process. Journal of Business and Psychology, 2, 306-310.

Jacobs, R., Kafry, D., \& Zedeck, S. (1980). Expectations of behaviorally anchored ratings scales. Personnel Psychology, 33, 595-640.

Kahn, R. L., \& Antonucci, T. C. (1980). Convoys over the life course: Attachment, roles, and social support. In P.B. Baltes \& O. Brim (Eds.), Life-span development and behavior (Vol. 3). New York: Academic Press.

Kanfer, R. \& Ackerman, P. L. (2004). Aging, adult development, and work motivation. Academy of Management Review, 29, 440-458.

Karp, H., Fuller, C., \& Sirias, D. (2001). Bridging the boomer gap: Creating authentic teams for high performance at work. Palo Alto, CA: Daris Black Publishing. 
Kirchmeyer, C. (1995). Demographic similarity to the workgroup: A longitudinal study of managers at the early career stage. Journal of Organizational Behavior, 16, 67-83.

Kluger, A. N. \& DeNisi, A. (1996). The effects of feedback interventions on performance: A historical review, a meta-analysis, and a preliminary feedback intervention theory. Psychological Bulletin, 119, 254-284.

Konovsky, M. A. \& Cropanzano, R. S. (1991). Perceived fairness of employee drug testing as a predictor of employee attitudes and job performance. Journal of Applied Psychology, 76, 698-707.

Kooji, D. T. A. M., Jansen, P. G. W., Dikkers, J. S. E., \& De Lange, A. H. (2010). The influence of age on the associations between HR practices and both affective commitment and job satisfaction: A meta-analysis. Journal of Organizational Behavior, 31, 1111-1136.

Kupperschmidt, B. R. (2000). Multigeneration employees: Strategies for effective management. The Health Care Manager, 19, 65-76.

Lai, G. (1995). Work and family roles and psychological well-being in urban China. Journal of Health and Social Behavior, 36, 11-37.

Landy, F. J. \& Farr, J. L. (1980). Performance rating. Psychological Bulletin, 87, 72107.

Lang, F. R. \& Carstensen, L. L. (2002). Time counts: Future time perspective, goals, and social relationships. Psychology and Aging, 17, 125-139. 
Larson, R., Zuzanek, J., \& Mannell, R. (1985). Being alone versus being with people: Disengagement in the daily experience of older adults. Journal of Gerontology, 40, 375-381.

Law, K. S., Wong, C., Wang, D., \& Wang, L. (2000). Effect of supervisorsubordinate quanxi on supervisory decisions in China: An empirical investigation. The International Journal of Human Resource Management, 11, 751-765.

Lee, F. K., Sheldon, K. M., \& Turban, D. B. (2003). Personality and the goal-striving process: The influence of achievement goal patterns, goal level, and mental focus on performance and enjoyment. Journal of Applied Psychology, 88, 256-265.

Lefkowitz, J. (2000). The role of interpersonal affective regard in supervisory performance ratings: A literature review and proposed causal model. Journal of Occupational and Organizational Psychology, 73, 67-85.

Leung, K., Su, S., \& Morris, M. W. (2001). When is criticism not constructive? The roles of fairness perceptions and dispositional attributes in employee acceptance of critical supervisory feedback. Human Relations, 54, 1155-1187.

Levin, J. S. \& Chatters, L. M. (1998). Religion, health, and psychological well-being in older adults. Journal of Aging and Health, 10, 504-531.

Levy, P. E. \& Williams, J. R. (2004). The social context of performance appraisal: A review and framework for the future. Journal of Management, 30, 881-905.

Locke, E. A. \& Latham, G. P. (2002). Building a practically useful theory of goal setting and task motivation: A 35-year odyssey. American Psychologist, 57, 705717. 
Locke, E. A. \& Latham, G. P. (2006). New directions in goal-setting theory. Current Directions in Psychological Science, 15, 265-268.

Li, J. T., Tsui, A. S., \& Weldon, E. (2000). Management and organizations in the Chinese context. New York, NY: St. Martin's Press.

Liebold, M. \& Voepel, S. (2006). Managing the aging workforce: Challenges and solutions. Germany: Wiley Publishing.

Mabe, P. \& West, S. (1982). Validity of self-evaluation of ability: A review and meta-analysis. Journal of Applied Psychology, 67, 280-296.

Mather, M. \& Carstensen, L. L. (2003). Aging and attentional biases for emotional faces. Psychological Science, 14, 409-415.

Masterson, S. S., Byrne, Z. S., \& Mao, H. (2005). Interpersonal and information justice: Identifying the differential antecedents of interactional justice behaviors. In S. W. Gilliland, D. D. Steiner, D. P. Skarlicki, \& K. van den Bos (Eds.), What Motivates Fairness in Organizations? (79-103). Greenwich, CT: Information Age Publishing.

Masterson, S. S., Lewis, K., Goldman, B. M., \& Taylor, M. S. (2000). Integrating justice and social exchange: The differing effects of fair procedures and treatment on work relationships. Academy of Management, 43, 738-748.

McAuley, E., Blissmer, B., Marquez, D. X., Jerome, G. J., Kramer, A. F., \& Katula, J. (2000). Social relations, physical activity, and well-being in older adults. Preventive Medicine, 31, 608-617. 
McClelland, G. \& Judd, C. (1993). Statistical difficulties of detecting interactions and moderator effects. Psychological Bulletin, 114, 376-390.

Moorman, R. H. (1991). Relationship between organizational justice and organizational citizenship behaviors: Do fairness perceptions influence employee citizenship? Journal of Applied Psychology, 76, 845-655.

Morris, M. G. \& Venkatesh, V. (2000). Age differences in technology adoption decisions: Implications for a changing workforce. Personnel Psychology, 53, 375403.

Namov, A. \& Puffer, S. (2000). Measuring Russian culture using Hofstede’s dimensions. Applied Psychology, 49, 709-718.

Ng, T. W. H. \& Feldman, D. C. (2008). The relationship of age to ten dimensions of job performance. Journal of Applied Psychology, 93, 392-423.

Ogilvie, D. M., Rose, K. M., \& Heppen, J. B. (2001). A comparison of personal project motives in three age groups. Basic and Applied Social Psychology, 23, 207-215.

Payne, H. \& Makiney, J. (April, 2008).Generational differences in workplace performance and employee engagement. Paper presented at the 2008 Annual Meeting of the Society for Industrial/Organizational Psychologists: San Francisco, CA.

Pearce, J.L. \& Porter, L.W. (1986). Employee responses to formal performance appraisal feedback. Journal of Applied Psychology, 71, 211-218. 
Pedler, M. \& Boydell, T. (1980). Is all management development self-development? In J. Beck \& C. Cox (Eds.), Advances in management education(165-196). New York: Wiley Publishing.

Podsakoff, P.M. \& Farh, J.-L. (1989). Effects of feedback sign and credibility on goal setting and task performance. Organizational Behavior and Human Decision Processes, 44, 45-67.

Prinz, W. (1997). Perception and action planning. European Journal of Cognitive Psychology, 9, 129-154.

Pritchard, R. D., Jones, S. D., Roth, P. L., Stuebing, K. K., \& Ekeburg, S. E. (1988). Effects of group feedback, goal setting, and incentives on organizational productivity. Journal of Applied Psychology, 73, 337-358.

Rocco, T. S., Stein, D., \& Lee, C. (2003). An exploratory examination of the literature on age and HRD policy development. Human Resource Development Review, 2, 155-180.

Russell, J.A. (1980). A circumplex model of affect. Journal of Personality and Social Psychology, 39, 1161-1178.

Schein, V. E., Mueller, R., Lituchy, T., \& Liu, J. (1998). Think manager-think male: A global phenomenon? Journal of Organizational Behavior, 17, 33-41.

Schraeder, M. \& Simspon, J. (2006). How similarity and liking affect performance appraisals. The Journal for Quality and Participation, 29, 34-54.

Schrauger, J. S. (1975). Responses to evaluation as a function of initial selfperceptions. Psychological Bulletin, 82, 581-596. 
Scullen, S. E., Mount, M. K., \& Goff, M. (2000). Understanding the latent structure of job performance ratings. Journal of Applied Psychology, 85, 956-970.

Selwyn, N. (2004). The information aged: A qualitative study of older adults' use of information and communications technology. Journal of Aging Studies, 18, 369384.

Smith, R. E. \& Swinyard, W. R. (1983). Attitude-behavior consistency: The impact of product trial versus advertising. Journal of Marketing Research, 20, 257-267.

Smola, K. W. \& Sutton, C. D. (2002). Generational differences: Revisiting generational work values for the new millennium. Journal of Organizational Behavior, 23, 363-382.

Steers, R. M., Porter, L. W., \& Bigley, G. A. (1996). Motivation and leadership at work. New York: McGraw Hill.

Strauss, J. P., Barrick, M. R. , \& Connerley, M. L. (2001). An investigation of personality similarity effects (relational and perceived) on peer and supervisor ratings and the role of familiarity and liking. Journal of Occupational and Organizational Psychology, 74, 637-657.

Sutton, S. (1998). Predicting and explaining intentions and behavior: How well are we doing? Journal of Applied Social Psychology, 28, 1317-1338.

Swanson, J. L. \& D’Achiardi, C. (2005). Beyond interests, needs/values, and abilities: Assessing other important career constructs over the lifespan. In S. D. Brown \& R. W. Lent (Eds.), Career Development and Counseling: Putting theory and research to work. Hoboken, NJ: Wiley \& Sons. 
Taylor, M. S., Fisher, C. D., \& Ilgen, D. R. (1984). Individuals' reactions to performance feedback in organizations: A control theory perspective. In K. M. Rowland \& G. R. Ferris (Eds.), Research in personnel and human resources management (pp. 81-124). Greenwich, CT: JAI Press.

Thorndike, E.L. (1927). The law of effect. American Journal of Psychology, 39, 212222.

Troll, L. E. \& Skaff, M. M. (1997). Perceived continuity of self in very old age. Psychology and Aging, 12, 162-169.

Tsui, A. S. \& O’Reilly, C. A. (1989). Beyond simple demographic effects: The importance of relational demography in superior-subordinate dyads. Academy of Management Journal, 32, 402-423.

Turk-Charles, S., Mather, M., \& Carstensen, L. L. (2003). Aging and emotional memory: The forgettable nature of negative images for older adults. Journal of Experimental Psychology, 132, 310-324.

Twenge, J. M. \& Campbell, S. M. (2008). Generational differences in psychological traits and their impact on the workplace. Journal of Managerial Psychology, 23, $862-877$.

Twenge, J. M., Campbell, S. M., Hoffman, B. J., \& Lance, C. E. (2010). Generational differences in work values: Leisure and extrinsic values increasing, social and intrinsic values decreasing. Journal of Management, 36, 1117-1142. 
Utz, R. L., Carr, D., Nesse, R., \& Wortman, C. B. (2002). The effect of widowhood on older adults' social participation: An evaluation of activity, disengagement, and continuity theories. The Gerontologist, 42, 522-533.

Walker, A. (2005). The emergence of age management in Europe. International Journal of Organizational Behavior, 10, 685-697.

Warr, P. (1994). Age and job performance. In J. Snel \& R. Cremer (Eds.), Work and Aging: A European Perspective (pp. 309-326). Bristol, PA: Taylor \& Francis.

Wiggins, J. S., \& Trapnell, P. D. (1996). A dyadic-interactional perspective of the five factor model. In J. S. Wiggins (Ed.), The five-factor model of personality: Theoretical perspectives (pp. 88-162). New York: Guilford Press.

Wolf, L. F. \& Smith, J. K. (1995). The consequence of consequence: Motivation, anxiety, and test performance. Applied Measurement in Education, 8, 227-242.

Wong, M., Gardner, E., Lang, W., \& Coulon, L. (2008). Generational differences in personality and motivation: Do they exist and what are the implications for the workplace? Journal of Managerial Psychology, 23, 878-890.

Zepelin, H. (1978). Is age becoming irrelevant? An exploratory study of perceived age norms. International Journal of Aging and Human Development, 24, 241-256. 